NBER WORKING PAPER SERIES

\title{
RISK PERCEPTIONS AND PROTECTIVE BEHAVIORS: EVIDENCE FROM COVID-19 PANDEMIC
}

\author{
M. Kate Bundorf \\ Jill DeMatteis \\ Grant Miller \\ Maria Polyakova \\ Jialu L. Streeter \\ Jonathan Wivagg \\ Working Paper 28741 \\ http://www.nber.org/papers/w28741 \\ NATIONAL BUREAU OF ECONOMIC RESEARCH \\ 1050 Massachusetts Avenue \\ Cambridge, MA 02138 \\ April 2021
}

Corresponding author: Maria Polyakova (mpolyak@stanford.edu). We are grateful to Sarah Boegl and Aava Farhadi for excellent research assistance. We have made the deidentified survey dataset used in this manuscript available at https://covid19.richdataservices.com/westat/ westat_covid_2020/. We gratefully acknowledge in-kind survey support from Westat. The views expressed herein are those of the authors and do not necessarily reflect the views of the National Bureau of Economic Research.

NBER working papers are circulated for discussion and comment purposes. They have not been peer-reviewed or been subject to the review by the NBER Board of Directors that accompanies official NBER publications.

(C) 2021 by M. Kate Bundorf, Jill DeMatteis, Grant Miller, Maria Polyakova, Jialu L. Streeter, and Jonathan Wivagg. All rights reserved. Short sections of text, not to exceed two paragraphs, may be quoted without explicit permission provided that full credit, including $(\odot$ notice, is given to the source. 
Risk Perceptions and Protective Behaviors: Evidence from COVID-19 Pandemic

M. Kate Bundorf, Jill DeMatteis, Grant Miller, Maria Polyakova, Jialu L. Streeter, and Jonathan

Wivagg

NBER Working Paper No. 28741

April 2021

JEL No. H0,I1

\begin{tabular}{|c|c|}
\hline \multicolumn{2}{|c|}{ ABSTRACT } \\
\hline \multicolumn{2}{|c|}{$\begin{array}{l}\text { We analyze data from a survey we administered during the COVID-19 pandemic to investi } \\
\text { the relationship between people's subjective risk beliefs and their protective behaviors. We re } \\
\text { three main findings. First, on average, people substantially overestimate the absolute level of } \\
\text { associated with economic activity, but have correct signals about their relative risk. Secc } \\
\text { people who believe that they face a higher risk of infection are more likely to report avoic } \\
\text { economic activities. Third, government mandates restricting economic behavior attenuate } \\
\text { relationship between subjective risk beliefs and protective behaviors. }\end{array}$} \\
\hline M. Kate Bundorf & Maria Polyakova \\
\hline Sanford School of Public Policy & Center for Health Policy \\
\hline Duke University & Stanford School of Medicine \\
\hline Durham, NC 27708 & Encina Commons, Room 182 \\
\hline and NBER & 615 Crothers Way \\
\hline kate.bundorf@duke.edu & $\begin{array}{l}\text { Stanford, CA } 94305 \\
\text { and NBER }\end{array}$ \\
\hline Jill DeMatteis & maria.polyakova@stanford.edu \\
\hline \multicolumn{2}{|l|}{ Westat } \\
\hline JillDematteis@westat.com & $\begin{array}{l}\text { Jialu L. Streeter } \\
\text { Stanford Center on Longevity }\end{array}$ \\
\hline Grant Miller & Stanford University \\
\hline Center for Health Policy/ & 365 Lasuen St. \\
\hline Center for Primary Care \& Outcomes Research & Stanford, CA 94305 \\
\hline Stanford University & jialu.streeter@stanford.edu \\
\hline 615 Crothers Way & \\
\hline Stanford, CA 94305-6006 & Jonathan Wivagg \\
\hline and NBER & Westat \\
\hline ngmiller@stanford.edu & JonathanWivagg@westat.com \\
\hline
\end{tabular}

Data is available at https://covid19.richdataservices.com/westat/westat_covid_2020/ 


\section{Introduction}

Subjective perceptions of risk guide decision making in nearly all economic domains (Hurd, 2009). While a rich theoretical literature highlights the importance of subjective beliefs for individual actions, fewer studies provide empirical evidence of the link between risk perceptions and behaviors, particularly in non-laboratory settings and in high-income countries (Peltzman, 1975; Delavande, 2014; Delavande and Kohler, 2015; Mueller et al., 2021). Yet, knowing how subjective risk perceptions influence behavior is essential for policy development. Many policies, such as government insurance mandates and public health campaigns, seek to change behavior in the presence of risk. Predicting responses to such policies requires understanding how policies influence perceived risks and, in turn, how risk beliefs influence behaviors (Manski, 2004).

We examine the relationship between individual perceptions of (a very salient) risk and economic behaviors, as well as how much people believe policy interventions change that relationship. Our analysis is based on a nationally representative survey we fielded in the United States in May of 2020, near the beginning of the COVID-19 pandemic. We collected information on individual beliefs regarding COVID-19 risks, including both the likelihood of infection and the likely health implications of infection, how much people changed their activities in response to the pandemic, and how much they believed they would have changed their activities in a hypothetical scenario without government restrictions on activities.

We report three main findings. First, most people substantially overestimated the absolute level of risk associated with engaging in economic activity early in the pandemic. On average, participants reported that their risk of contracting COVID-19 while performing an economic activity was $40 \%$ to $62 \%$, depending on the activity. The actual prevalence of COVID-19, however, was much lower. By May 31, 2020, the U.S had reported 1,786,683 cumulative cases or a prevalence of $0.5 \% .^{1}$ This is consistent with research indicating that people often overestimate both small and highly publicized risks (Viscusi et al., 1998). At the same time, people had more accurate perceptions about their relative risks. Individual assessment of risk varied substantially across socio-economic and demographic groups as well as across geographies in ways that are consistent

\footnotetext{
${ }^{1}$ CDC Covid Tracker.
} 
with observational data on the variation in COVID-19 prevalence and outcomes.

Second, we find that individual beliefs about COVID-19 risks were related to individual protective behavior. In the early stages of the COVID-19 pandemic, minimizing interpersonal interactions through activity reduction was arguably the most effective protective behavior available to reduce infection risk. Our results indicate that those who believed that they had a higher risk of infection also believed that, in the absence of policies restricting economic activity, they would reduce their activities more in response to the pandemic across a variety of domains. This result builds on work in economic epidemiology which emphasizes the endogeneity of private protective behavior with respect to disease prevalence (Philipson, 2000). Relating COVID-19 prevalence and behaviors directly, we find prevalence elasticities (a measure of responsiveness of individual protective behaviors to disease outbreak) ranging from 0.02 to 0.77 across different domains of avoidance behavior and policy environments.

Finally, we find that individuals believe that the decisions they made about economic behavior in the presence of a government-mandated shelter-in-place (SIP) order differ substantially from those they would have made in the absence of such an order, with public mandates for activity restriction attenuating the relationship between subjective risk perceptions and behavior. Our findings suggest that government mandates may reduce the externality that lower risk individuals (who may privately choose to invest in less protective behaviors) exert on higher risk individuals (McAdams, 2021; Adda, 2016). In fact, we find suggestive evidence that people who believe that they are higher risk for negative outcomes conditional on infection are more likely to engage in economic activity in the presence of a government SIP order than those who are lower risk, consistent with policies which reduce risk leading to off-setting increases in risky behavior (Ehrlich and Becker, 1972; Shavell, 1979).

Narrowly, our paper contributes to the rapidly growing literature on the COVID-19 pandemic, and especially the role of private beliefs and government policies in driving behaviors. Studies aimed at measuring the effect of government policies have used either microsimulation models (Davies et al., 2020; Ferguson et al., 2020; Jarvis et al., 2020; Ngonghala et al., 2020; Peak et al., 2020; Prem et al., 2020) or, increasingly, retrospective analyses of policy implementation (Chen et al., 2020; 
Abouk and Heydari, 2021; Nguyen et al., 2020; Dave et al., 2021; Chudik et al., 2020; Glaeser et al., 2020; Gupta et al., 2020; Flaxman et al., 2020; Alexander and Karger, 2020; Klein et al., 2020a,b; Jacobsen and Jacobsen, 2020; Weill et al., 2020; Atkeson et al., 2020). Several studies have examined risk perceptions during the pandemic, including Alsan et al. (2020); Bordalo et al. (2020); Wise et al. (2020); Barrios and Hochberg (2020); Fan et al. (2020); Cori et al. (2020); Plohl and Musil (2021). Most studies of SIP policies, however, have placed relatively emphasis on subjective risk perceptions and their relationship with individual, private decisions regarding risk protection.

While the empirical patterns that we document are specific to the COVID-19 context, our findings contribute to the literature on eliciting subjective risk beliefs to understand how people make decisions under risk (Manski, 2004; Hurd, 2009; Delavande, 2014; Delavande and Kohler, 2015; Spinnewijn, 2013; Handel and Kolstad, 2015; Miller et al., 2020; Mueller et al., 2021). Further, our results on the role of SIP policies contribute new empirical evidence to a much broader literature on the ability of government interventions to reduce informational externalities. For example, a SIP mandate, which we find reduces differences in behavior across individuals with different beliefs about risk, is conceptually similar to a mandate in markets with asymmetric information that equalizes the take-up of insurance across people with different private information about risk (Cutler et al., 2008; Einav et al., 2010; Hendren, 2013; Hackmann et al., 2015).

\section{Data and Empirical Analysis}

\subsection{Survey design}

In the very early stages of the COVID-19 pandemic, we developed a survey instrument aiming to evaluate knowledge about COVID-19 and daily behaviors among people in the United States. The survey was administered by Westat, a survey research firm, between May 7 and May 26 . Researchers at Westat randomly selected 13,590 residential addresses across the U.S. and mailed them an invitation to participate in an on-line survey. The addresses were selected from the Delivery Sequence File maintained by the U.S. Postal Service through an authorized vendor.

The invitation letter included a $\$ 1$ cash incentive and told respondents they had the opportunity 
to contribute to policy development related to the COVID-19 pandemic and that they would receive $\$ 5$ for completing the survey. To accommodate within-household sampling for addresses with multiple adult residents, the invitation letter randomly included instructions for the youngest male, oldest male, youngest female, or oldest female in the household to complete the survey. Alternate instructions asked either the oldest or youngest adult of the opposite sex to complete the survey if there were no males/females in the household. The invitation included a link to a website and a participant code that the respondents used to access the on-line survey. After completing the survey, the respondents were asked to provide their mailing address if they wanted to receive the $\$ 5$ honorarium. Honoraria were mailed on June 5, 2020. 1,222 out of 13,590 individuals completed the survey - a response rate of $10 \%$ after accounting for non-deliverable addresses.

The survey contained questions about the risk of contracting the virus and behavioral responses to the COVID-19 pandemic across several domains. Appendix A.2 replicates the key questions from the survey instrument. We asked respondents to indicate whether there were directions from their governor or officials to stay or home or shelter in place. For all respondents, we asked how the time they spent on activities such as grocery shopping and dining in restaurants had changed since before the pandemic. For those responding that there were SIP restrictions active at the time of the survey, we asked how the time they spent on each activity would have changed if there had been no directions to stay at home. For those without SIP restrictions, we asked how their behaviors would have changed if restrictions had been in place. As $92 \%$ of survey respondents indicated that a SIP policy was active in their area of residence, we focus only on this group of individuals in our empirical analysis. ${ }^{2}$

\subsection{Empirical Specifications}

Heterogeneity in Subjective Risk Beliefs Our survey instrument directly asked individuals to evaluate their risk of contracting COVID-19 (on a scale from 0\% to 100\%) while performing

\footnotetext{
${ }^{2}$ Individuals' knowledge of whether there was a SIP order in their county of residence was nearly always accurate. 1,100 out of 1,219 respondents correctly reported that SIP was in place in their place of residence (we verified the county's SIP status as of April 272021 based on Lin (2020); Baker-McKenzie (2020); Mervosh et al. (2020); Semerad (2020); Sylte et al. (2020); Gross (2020)). 22 individuals correctly reported that they were not subject to a SIP at the time of our survey. 70 individuals had an incorrect belief about having or not having a SIP order in their area, while 27 reported not knowing if they were subject to a SIP.
} 
the following economic activities: 1) seeing a movie in a theater, 2) eating in a restaurant (not including take-out or delivery), 3) using shared transportation such as commercial flights, trains, buses, or shared ride services, 4) personal services such as haircuts or manicures or going to the gym, 5) grocery shopping. The activities include some that are more discretionary (seeing a movie) and some that are less discretionary (grocery shopping). We also asked survey participants about their subjective beliefs regarding the risk of outcomes conditional on infection. This set of questions included the request to assess the likelihood that individuals would (1) have symptoms; (2) need medical care; (3) need to be hospitalized; (4) die if they caught the coronavirus; (5) have (insufficient) staff and supplies for treatment in a hospital. We convert the answers to these questions into a severity index by taking an unweighted mean of the five underlying indicator variables.

We start our analysis by examining how the average level of subjective beliefs about risk compares to the level of COVID-19 prevalence reported by the Centers for Disease Control and Prevention, ${ }^{3}$ and the extent to which risk beliefs vary across individuals. We next ask if individuals' subjective beliefs contain correct signals about differences in relative risk across either geographic locations or demographic groups. We use data on county-level COVID-19 prevalence, as reported by usafacts.org in May 2020, as a measure of geographic risk exposure. We use demographic and socio-economic characteristics of individuals as self-reported in the survey. The regression equations take the following form:

$$
\begin{gathered}
\operatorname{Risk}_{i(c)}^{a}=\alpha_{0}^{a}+\alpha_{1}^{a} D_{i}+\gamma^{a} X_{c(i)}+\epsilon_{i}^{a} \\
\operatorname{Risk}_{i(c)}^{a}=\kappa_{0}^{a}+\kappa_{1}^{a} G_{\text {GeoPrevalence }}(i)+\phi^{a} X_{c(i)}+\eta_{i}^{a}
\end{gathered}
$$

where $\operatorname{Risk}_{i(c)}^{a}$ is a continuous variable between 0 and 1 that measures the reported probability of contracting COVID-19 if the individual $i$ residing in county $c$ performed activity $a . D_{i}$ is a vector of demographic characteristics that includes: age (discretized into groups of (18-30 years, 30-44, 45-59, and 60+), sex, race (Hispanic, non-Hispanic Black, other), marital status (indicator for being married), education (indicator for having a Bachelor's degree or above), self-reported health status (indicator for having at least one of seven chronic health conditions, including high blood pressure,

\footnotetext{
${ }^{3}$ https://covid.cdc.gov/covid-data-tracker
} 
diabetes, depression/anxiety, heart disease, respiratory diseases, kidney disease, and autoimmune disorder). $X_{c(i)}$ is the number of days since the SIP order had been enacted. Equation 2 is an analogous specification that measures the relationship between perceived risks and the geographic prevalence of infection-GeoPrevalence $_{c(i)}$ is the county-level number of COVID-19 cases per 1,000 in May 2020. The coefficients of interest are $\alpha_{1}^{a}$ and $\kappa_{1}^{a}$ for each activity $a$ that measure whether true variation in risk exposure across demographics or geography is predictive of individuals' subjective risk perceptions from engaging in activity $a$. All estimating equations are weighted with survey weights and replicate jackknife weights are used to compute standard errors.

Private Beliefs and the Choice of Preventive Behaviors Our survey asked respondents to report how much more or less they went grocery shopping, used personal services, ate in a restaurant, saw movies in a theater, or used shared transportation since the beginning of the pandemic. The response categories for each activity included: 1) decreased a lot (by more than $50 \%$ ), 2) decreased somewhat (by less than 50\%), 3) has not changed, 4) increased somewhat (by less than 50\%), 5) increased a lot (by more than 50\%), 6) I didn't do this before the pandemic before the pandemic.

For our baseline analysis of the relationship between beliefs and behaviors we create a simple indicator variable for the respondent having reduced an economic activity by a lot (more than $50 \%$ ). Then, for each activity $a$ we estimate a linear probability model:

$$
Y_{i(c)}^{a}=\beta_{0}^{a}+\beta_{1}^{a} R i s k_{i}^{a}+\lambda^{a} X_{c(i)}+\nu_{i}^{a}
$$

Where, $Y_{i(c)}^{a}$ is an indicator that takes a value of 1 of individual $i$ living in county $c$ reduced activity a by more than $50 \%$ ("by a lot"), Risk $k_{i}^{a}$ is a continuous variable between 0 and 1 that measures the subjective probability of contracting COVID-19 if the individual performed activity $a$ as well as the index of beliefs about disease severity. We include the index of beliefs about disease severity in a regression for each activity $a$, as beliefs about severity conditional on contracting the disease are not activity-specific. The vector of control variables $X_{c(i)}$ includes the number of days since the SIP order had been enacted. Because perceptions about the underlying level of risk 
vary widely across individuals, $X_{c(i)}$ also includes beliefs about the risk of infection when staying at home in all specifications. This adjusts for the baseline differences in risk perception levels. The coefficients of interest are $\beta_{1}^{a}$ that measure how much more or less likely individuals were to undertake an economic activity $a$ if they had a one percentage point higher subjective assessment of COVID-19 risk.

We report the results of an ordinal regression model that does not collapse responses into one indicator variable for "reducing activity by a lot" in Appendix Table A.2. In Appendix Table A.3 we further report the results of the baseline regression using a sub-sample that excludes individuals who reported not participating in an activity before the pandemic. Qualitatively, the results of these analyses are similar to the baseline.

Perceived Role of Public Policies To assess the role of public policies in mediating the relationship between beliefs and behaviors, we asked respondents to report how much they believe they would have changed their behavior in a hypothetical scenario without a SIP order. By comparing responses in the hypothetical scenario to the reports of the actual behavioral change, we can assess how much importance individuals ascribe to the SIP policy.

We re-estimate Equation 3 using responses to the hypothetical scenario. We then compare the behavior-belief elasticity as captured by $\beta_{1}$ between the observed and the counterfactual regime. A lower counterfactual elasticity would suggest that individuals believe that government intervention is attenuating the effect of their own risk assessment on decision-making, while a higher counterfactual elasticity would suggest that policy interventions and beliefs are complements. In the limit, a policy intervention that removes any association between subjective beliefs and behaviors (as, for instance, would be the case if all individuals were forced to stay at home) would homogenize behavioral responses of agents with heterogeneous beliefs. This intuition about the role of government mandate as an equalizer of behavioral responses across individuals with different beliefs applies to many settings outside of the infectious disease environment. For instance, a government mandate to pay into any type of social insurance program equalizes coverage purchase decisions across individuals with different beliefs about risks. 


\section{Results}

\subsection{Summary Statistics}

1,365 individuals started our survey, and 1,222 individuals completed it. Our analytic sample is comprised of 1,127 individuals $(92.2 \%)$ who reported being subject to an active SIP order at the time of the survey. Table 1 reports the summary statistics for this analytic sample. While the original survey was mailed to a nationally representative draw of postal addresses, which individuals decided to respond to the survey is not random. We weight the summary statistics with survey weights to account for nonrandom non-response on observables. The average age of respondents is 47. $49 \%$ of individuals are male. $16 \%$ are Hispanic individuals while $9 \%$ are non-Hispanic Black individuals. $53 \%$ are married, $31 \%$ have a Bachelor's degree or above, and $55 \%$ reported having at least one underlying chronic health condition among hypertension, diabetes, depression or anxiety, heart disease, a respiratory disease, kidney disease, or an autoimmune disorder. $28 \%$ reported to be an essential worker.

\subsection{Heterogeneity in Subjective Beliefs}

Figure 1 plots the distribution of probability elicitations for contracting COVID-19 while engaging in different types of economic activities. Two facts are apparent from the data. First, people vastly overestimated the risk of contracting COVID-19 on average (as is common in surveys eliciting subjective probabilities, see Hurd, 2009; Belot et al., 2020). An average respondent believed there was a $40 \%$ risk of contracting COVID-19 when going to a grocery store and a $62 \%$ chance when sharing transportation. These belief elicitations were collected in May 2020. In May, the number of cumulative COVID-19 cases in the US was approaching 2 million (AJMC.com, 2020), while the 7-day moving average of new cases oscillated between 20,000 and 25,000 people. Both measures

imply that the objective risk of contracting the disease was substantially lower than what survey respondents believed. Figure 1 also demonstrates that individual beliefs were highly heterogeneous, spanning the full support of the probability measure. As is common in the subjective belief elicitation data (Kleinjans and van Soest, 2014), we observe a concentration of responses around the focal 
point of $50 \%$ probability ( $15 \%$ to $30 \%$ of responses) for all categories of risk; however, substantial mass of the distribution also lies both to the left and to the right of $50 \%$.

Figure 2 examines whether heterogeneity across individuals in their risk beliefs correlates with heterogeneity in their objective risk. Appendix Table A.1 reports the tabular version of the same regression output. For each demographic variable, Panel A of Figure 2 presents the estimates of $\alpha_{1}^{a}$ from Equation 1 for activities $a \in$ (risk movies, restaurant, transport, service, grocery). The point estimates and $95 \%$ confidence intervals for these activities are marked in shades of blue. Several patterns emerge. First, men believe that they face a lower risk of infection than women when performing any activity. Second, Hispanic Americans believe that they face a higher risk of contracting an infection than white Americans. Non-Hispanic Black Americans also report higher perceived risk of infection (although we lack statistical power to conclude that this difference is significant). Third, individuals with pre-existing health conditions believe that they have a higher probability of infection. Dark grey markers and confidence intervals report the estimate of $\alpha_{1}^{a}$ from Equation 1 for the index measure of individuals' beliefs about serious disease complications if infected as the outcome variable. Older individuals, Black individuals, Hispanic individuals, and those with pre-existing health conditions all believe that they are more likely to experience serious complications if infected. By contrast, individuals with a Bachelor's degree or higher believe that they are less likely to have a more severe disease course.

In Panel B of Figure 2, we examine the relationship between area-level prevalence and risk beliefs. While the estimates are imprecise, they are generally positive and represent a substantive effect. For example, a change from the 25th to the 75th percentile in COVID-19 cases (2.24 per $1,000)$ is associated with an increase of 0.11 in the subjective probability of infection when going to a restaurant, representing a 22 percent increase relative to the mean (0.51).

In most cases, these findings are consistent with the epidemiologic evidence on the relationship between demographic characteristics and COVID-19 risk. In particular, Hispanic and Black Americans seem to be correctly aware of their heightened risk in the incidence and severity of COVID-19 relative to other demographic groups (Ogedegbe et al., 2020; Muñoz-Price et al., 2020; Van Dyke et al., 2021). In the case of age, we find no evidence of a positive age gradient in the belief of infection 
risk, despite dramatically higher rates of recorded infection among older adults during the time period of our study (CDC, 2020). Instead, those 60 and older in our sample consider themselves having a higher probability of complications conditional on infection than younger groups, consistent with observed risk (O'Driscoll et al., 2021). Our results directly contrast those of Bordalo et al. (2020) who report that older adults report a lower probability of death or hospitalization conditional on COVID-19 infection but are more consistent with those of other COVID-specific studies (Dryhurst et al., 2020). Gender differences in perceived risk, in contrast, are less consistent with documented disease patterns - while men have been documented to be at a higher risk of COVID-19 infection and worse outcomes (O'Driscoll et al., 2021), in our survey they consistently report lower risk of becoming infected than women. This type of "overconfidence" is consistent with evidence documented by Galasso et al. (2020) who find that men on average perceive lower personal risks associated with COVID-19 than women consistently across several high-income countries. These geographic and demographic heterogeneity patterns suggest that even though individuals overestimate the overall level of risk, their subjective beliefs often contain correct signals about the direction of relative risks.

\subsection{Private Beliefs and the Choice of Preventive Behaviors}

Figure 3 presents descriptive evidence of the extent to which people reduced activities under policies restricting activity and what they reported they would have done in the absence of those policies. People reported relatively large activity reductions in the presence of a SIP order. 40 percent of people reported reducing their activity by a lot for grocery shopping, while 79 percent of people reported reducing their activity by a lot for restaurant visits, consistent with grocery shopping being a more essential activity. The figure also shows the choice of activity reductions that individuals believe they would have made absent SIP orders. The reported reduction in activity is substantially smaller than under SIP policies, but it is far from zero. Between 21\% (for shared transportation) and $32 \%$ (for restaurants) of individuals report that they would have reduced the respective activities by a lot even in the absence of a formal SIP order. Thus, individuals clearly believe that SIP orders constrain their private choices, but they also believe that they would have undertaken substantial 
private preventive investments in the absence of government interventions.

In Table 2, we report the estimates of $\beta_{1}$ in Equation 3 for self-reported reductions in activity under existing SIP orders. Those believing that the infection risk associated with individual activities was greater were more likely to reduce those specific activities. For example, a 10 percentage point (19\% relative to the mean of 51.5 percentage points as reported in Figure 1) increase in the perceived probability of infection risk from eating in a restaurant is associated with a 2.5 percentage point increase in the probability that a respondent reduced restaurant visits by a lot (this corresponds to a $3.1 \%$ increase relative to the average probability of reducing restaurant activity by a lot, which was $79 \%$ in the sample as reported in Table 2). The estimate implies a behavior-belief elasticity of 0.16 for restaurant visits - a one percent increase in the subjective risk from a restaurant visit is associated with a 0.16 percent increase in the probability of reducing restaurant visits by a lot. The elasticity is also positive for the other activities we examined (ranging from 0.02 for movie theater to 0.20 for shared transportation), but less precise, lacking the statistical power to reject a zero elasticity at conventional confidence levels.

Taken together, our results are consistent with the existence of a non-zero prevalence elasticity between the true risk and behavioral decisions (Philipson, 2000; Oster, 2018) that is mediated through changes in risk beliefs. Above, we found that individuals who live in areas with a higher prevalence of risk report higher subjective risk elicitations. Here, we observe that having a higher subjective risk assessment is correlated with a stronger reduction in economic activity. The two results together imply that we would expect individuals in areas with a higher prevalence of risk to undertake more preventive behaviors and reduce their economic activities more. In Table 3 we measure the prevalence elasticity directly by correlating the geographic prevalence of COVID and the extent of economic activity reduction as reported by our survey respondents. We find that individuals in areas with a higher prevalence of COVID-19 were more likely to reduce their economic activity. The elasticity estimates (which measure the percent change in the probability of reducing an activity by a lot in response to a one percent higher prevalence of infections) range from 0.03 for movies, restaurants, and grocery shopping to 0.17 for shared transportation in the 
presence of government policies restricting economic activity. ${ }^{4}$

\subsection{Perceived Role of Public Policies}

In the second column of each column-pair in Table 2 we re-estimate the relationship between risk beliefs and privately-preferred activity reductions that respondents believe they would have chosen absent the SIP orders. In general, this counterfactual relationship is markedly stronger than the one under existing SIP orders. This is particularly true for more 'discretionary' services. For example, the point estimate for the relationship between risk beliefs and behavior is more than twice as large for the use of personal services in the absence of SIP (0.40) than when SIP is in place (0.16). Differences in the estimates of the relationship between perceived risk of infection and behavior reduction are statistically significant with a p-value for a two-sided test of $<0.1$ for movies, restaurants, and services.

As with belief-behavior relationship, the relationship between geographic prevalence of disease and activity reduction is stronger for the hypothetical scenario of no policy intervention. We estimate higher hypothetical prevalence elasticities for all economic activities, ranging from 0.11 for restaurants and personal services to 0.21 for shared transportation.

Higher belief-behavior and prevalence elasticities that we estimate for the counterfactual scenarios without "directions from your governor or other officials to stay at home or shelter-in-place" orders are consistent with individuals believing that public policy interventions are in fact constraining their private choices. Respondents believe that in the absence of SIP policies their own subjective beliefs about risk would have played a more important role in driving their behavioral choices.

\subsection{Risk of Infection versus Risk of Severe Disease}

The relationship between the perceived risk of a poor outcome conditional on infection and activity reductions also differs depending on whether SIP is in place. In the absence of SIP policies, we find no statistically significant association between activity reductions and beliefs regarding risk

\footnotetext{
${ }^{4}$ Note that this result is not mechanically driven by the existence of a SIP order as only individuals exposed to a SIP are included in our analysis.
} 
of complications for each activity, with the exception of grocery shopping. For grocery shopping, people who believe they are likely to experience complications if infected are more likely than those who perceive the risk to be low to reduce this activity a lot. By contrast, in the presence of SIP policies, those who believe that they face a greater risk of a serious complication if infected are less likely to reduce several activities by a lot. In other words, those at high risk of a poor outcome conditional on infection are more likely to maintain or increase the extent to which they go to a sit down restaurant and go to a movie theater than those who perceive themselves at lower risk. This is consistent with people with high perceived health risk reducing their protective behaviors relative to those with lower perceived risk when policies create a less risky environment. While this relationship differs for grocery shopping, we note that grocery shopping is typically exempt from SIP policies. Thus, the implementation of SIP is unlikely to reduce the risk associated with this activity.

\section{Conclusion}

We find that subjective assessments of risk are important determinants of economic activity. Our survey results suggest that a large share of Americans dramatically reduced their activities outside the home in response to the COVID-19 pandemic, and that perceptions of risk influenced these choices. Individuals varied in their perceptions of both the risk of infection and the risk of a poor outcome conditional on infection early in the COVID-19 pandemic. Given the crucial role of private beliefs in shaping behavior, an important question is how individual beliefs are formed and whether they reflect reality. Unlike prior work in the context of COVID-19 (Alsan et al., 2020; Bordalo et al., 2020), we find that differences in the perception of risks across demographic subgroups and different geographies generally correlate with known realities of the risk of contracting the disease (Benitez et al., 2020; Ford et al., 2020; Richardson et al., 2020; Polyakova et al., 2020, 2021). This finding of a positive relationship between risk perceptions and protective behaviors in the context of the COVID-19 pandemic is consistent with other recent studies (Dryhurst et al., 2020).

An implication of our results is that SIP policies equalize behavior restrictions, to some extent, across those with more disparate underlying beliefs about disease risk. In particular, our results 
imply that formal SIP orders are likely to be more constraining (relative to the level of activities that individuals would have chosen privately) for people who believe they have (and often indeed have) a lower risk of contracting a COVID-19 infection. We found that many respondents believe that they would have dramatically reduced their activities even in the absence of formal policies restricting such activities. These findings imply that epidemiologic models of SIP effects are likely to overestimate the effectiveness of the policy interventions, as individuals are likely to alter their behaviors even in the absence of interventions based on their beliefs about risks.

More generally our results indicate that when designing policies that aim to change individual behavior in the presence of risk, policy makers need to consider how subjective risk perceptions are formed and how they shape behavior.

\section{References}

Abouk, Rahi and Babak Heydari, "The Immediate Effect of COVID-19 Policies On Social Distancing Behavior in the United States," Public Health Reports, 2021, 136 (2), 245-252.

Adda, Jérôme, "Economic Activity and the Spread of Viral Diseases: Evidence from High Frequency Data," The Quarterly Journal of Economics, 2016, 131 (2), 891-941.

AJMC.com, "A Timeline of COVID-19 Developments in 2020," https://www.ajmc.com/view/atimeline-of-covid19-developments-in-2020. Accessed: 2021-04-15, 2020.

Alexander, Diane and Ezra Karger, "Do Stay-At-Home Orders Cause People To Stay At Home? Effects of Stay-At-Home Orders On Consumer Behavior," FRB of Chicago Working Paper No. WP-2020-12, 2020.

Alsan, Marcella, Stefanie Stantcheva, David Yang, and David Cutler, "Disparities in Coronavirus 2019 Reported Incidence, Knowledge, and Behavior Among US Adults," JAMA network open, 2020, 3 (6), e2012403-e2012403.

Atkeson, Andrew, Karen Kopecky, and Tao Zha, "Four Stylized Facts about COVID-19," NBER Working Paper No. 27719, 2020. 
Baker-McKenzie, "Extensive Texas Shelter-in-Place and Stay at Home Orders by County," Client Alert. www.bakermckenzie.com/en/insight/publications/2020/03/extensive-texas-shelterin-place-covid19. Accessed: 2021-04-15, 2020.

Barrios, John M and Yael Hochberg, "Risk Perception Through the Lens of Politics in the Time of the COVID-19 Pandemic," NBER Working Paper No. 27008, 2020.

Belot, Michèle, Syngjoo Choi, Julian C Jamison, Nicholas W Papageorge, Egon Tripodi, and Eline van den Broek-Altenburg, "Country Survey on COVID-19," IZA Discussion Paper, 2020.

Benitez, Joseph A, Charles J Courtemanche, and Aaron Yelowitz, "Racial and Ethnic Disparities in COVID-19: Evidence from Six Large Cities," NBER Working Paper No. 27592, 2020.

Bordalo, Pedro, Katherine B Coffman, Nicola Gennaioli, and Andrei Shleifer, "Older People are Less Pessimistic about the Health Risks of COVID-19," NBER Working Paper No. $27494,2020$.

CDC, "COVID-19 Stats: COVID-19 Incidence, by Age Group — United States, March 1-November 14, 2020," 2020.

Chen, Hui, Juntao Huo, Qingyan Fu, Yusen Duan, Hang Xiao, and Jianmin Chen, "Impact of Quarantine Measures On Chemical Compositions of PM2. 5 During the COVID-19 Epidemic in Shanghai, China," Science of the Total Environment, 2020, 743, 140758.

Chudik, Alexander, M Hashem Pesaran, and Alessandro Rebucci, "Voluntary and Mandatory Social Distancing: Evidence On COVID-19 Exposure Rates From Chinese Provinces and Selected Countries," NBER Working Paper No. 27039, 2020.

Cori, Liliana, Fabrizio Bianchi, Ennio Cadum, and Carmen Anthonj, "Risk Perception and COVID-19," Int. J. Environ. Res. Public Health, 2020, 17 (9). 
Cutler, David M., Amy Finkelstein, and Kathleen McGarry, "Preference Heterogeneity and Insurance Markets: Explaining a Puzzle of Insurance," American Economic Review, May 2008, 98 (2), 157-62.

Dave, Dhaval, Andrew I Friedson, Kyutaro Matsuzawa, and Joseph J Sabia, "When Do Shelter-in-Place Orders Fight COVID-19 Best? Policy Heterogeneity Across States and Adoption Time," Economic Inquiry, 2021, 59 (1).

Davies, Nicholas G, Adam J Kucharski, Rosalind M Eggo, Amy Gimma, W John Edmunds, Thibaut Jombart, Kathleen O'Reilly, Akira Endo, Joel Hellewell, Emily S Nightingale et al., "Effects of Non-Pharmaceutical Interventions On COVID-19 Cases, Deaths, and Demand For Hospital Services in the UK: a Modelling Study," The Lancet Public Health, 2020 .

Delavande, Adeline, "Probabilistic Expectations in Developing Countries," Annual Review of Economics, 2014, 6 (1), 1-20.

_ and Hans-Peter Kohler, "HIV/AIDS-related Expectations and Risky Sexual Behaviour in Malawi," The Review of Economic Studies, 08 2015, 83 (1), 118-164.

Dryhurst, Sarah, Claudia R Schneider, John Kerr, Alexandra LJ Freeman, Gabriel Recchia, Anne Marthe Van Der Bles, David Spiegelhalter, and Sander van der Linden, "Risk Perceptions of COVID-19 Around the World," Journal of Risk Research, 2020, pp. 113.

Dyke, Miriam E Van, Maria CB Mendoza, Wen Li, Erin M Parker, Brook Belay, Elizabeth M Davis, Joshua J Quint, Ana Penman-Aguilar, and Kristie EN Clarke, "Racial and ethnic disparities in COVID-19 incidence by age, sex, and period among persons agedi 25 years-16 US jurisdictions, January 1-December 31, 2020," Morbidity and Mortality Weekly Report, 2021, 70 (11), 382.

Ehrlich, Isaac and Gary S Becker, "Market Insurance, Self-Insurance, and Self-Protection," Journal of Political Economy, 1972, 80 (4), 623-648. 
Einav, Liran, Amy Finkelstein, and Paul Schrimpf, "Optimal Mandates and the Welfare Cost of Asymmetric Information: Evidence From the U.K. Annuity Market," Econometrica, 2010, 78 (3), 1031-1092.

Fan, Ying, a Yeşim Orhun, and Dana Turjeman, "Heterogeneous Actions, Beliefs, Constraints and Risk Tolerance During the COVID-19 Pandemic," NBER Working Paper No. 27211, 2020.

Ferguson, Neil, Daniel Laydon, Gemma Nedjati Gilani, Natsuko Imai, Kylie Ainslie, Marc Baguelin, Sangeeta Bhatia, Adhiratha Boonyasiri, Zulma Cucunuba Perez, Gina Cuomo-Dannenburg et al., "Report 9: Impact of Non-Pharmaceutical Interventions (NPIs) To Reduce COVID-19 Mortality and Healthcare Demand," WHO Collaborating Centre for Infectious Disease Modelling, Imperial College London, 2020.

Flaxman, Seth, Swapnil Mishra, Axel Gandy, H Juliette T Unwin, Thomas a Mellan, Helen Coupland, Charles Whittaker, Harrison Zhu, Tresnia Berah, Jeffrey W Eaton et al., "Estimating the Effects of Non-Pharmaceutical Interventions On COVID-19 in Europe," Nature, 2020, 584 (7820), 257-261.

Ford, Tiffany, Sarah Reber, and Richard V Reeves, "Race Gaps in COVID-19 Deaths Are Even Bigger Than They Appear," Up Front, 2020.

Galasso, Vincenzo, Vincent Pons, Paola Profeta, Michael Becher, Sylvain Brouard, and Martial Foucault, "Gender Differences in COVID-19 Related Attitudes and Behavior: Evidence From a Panel Survey in Eight OECD Countries," NBER Working Paper No. 27359, 2020.

Glaeser, Edward L, Ginger Zhe Jin, Benjamin T Leyden, and Michael Luca, "Learning From Deregulation: The Asymmetric Impact of Lockdown and Reopening on Risky Behavior during COVID-19," NBER Working Paper No. 27650, 2020.

Gross, Samantha, "Florida Partisan Divide on Coronavirus over Shelter-in-Place," Tampa Bay Times, 2020. 
Gupta, Sumedha, Thuy D Nguyen, Felipe Lozano Rojas, Shyam Raman, Byungkyu Lee, Ana Bento, Kosali I Simon, and Coady Wing, "Tracking Public and Private Response To the COVID-19 Epidemic: Evidence From State and Local Government Actions," NBER Working Paper No. 27027, 2020.

Hackmann, Martin B., Jonathan T. Kolstad, and Amanda E. Kowalski, "Adverse Selection and an Individual Mandate: When Theory Meets Practice," American Economic Review, March 2015, 105 (3), 1030-66.

Handel, Benjamin R. and Jonathan T. Kolstad, "Health Insurance for "Humans": Information Frictions, Plan Choice, and Consumer Welfare," American Economic Review, August 2015, 105 (8), 2449-2500.

Hendren, Nathaniel, "Private Information and Insurance Rejections," Econometrica, 2013, 81 (5), 1713-1762.

Hurd, Michael D, "Subjective Probabilities in Household Surveys," Annual Review of Economics, 2009, 1 (1), 543-562.

Jacobsen, Grant D and Kathryn H Jacobsen, "Statewide COVID-19 Stay-at-Home Orders and Population Mobility in the United States," World Medical \& Health policy, 2020.

Jarvis, Christopher I, Kevin Van Zandvoort, Amy Gimma, Kiesha Prem, Petra Klepac, G James Rubin, and W John Edmunds, "Quantifying the Impact of Physical Distance Measures On the Transmission of COVID-19 in the UK," BMC medicine, 2020, 18, $1-10$.

Klein, Brennan, T LaRocky, S McCabey, L Torresy, Filippo Privitera, Brennan Lake, Moritz UG Kraemer, John S Brownstein, David Lazer, Tina Eliassi-Rad et al., "Assessing Changes in Commuting and Individual Mobility in Major Metropolitan Areas in the United States During the COVID-19 Outbreak," Northeastern University. Network Science Institute. Retrieved from https://www.networkscienceinstitute.org/publications/assessing- 
changes-in-commuting-and-individual-mobility-in-major-metropolitan-areas-in-the-united-statesduring-the-covid-19-outbreak, 2020.

_, Timothy LaRock, Stefan McCabe, Leo Torres, Lisa Friedland, Filippo Privitera, Brennan Lake, Moritz UG Kraemer, John S Brownstein, David Lazer et al., "Reshaping a Nation: Mobility, Commuting, and Contact Patterns During the COVID-19 Outbreak," Northeastern University-Network Science Institute Report. Retrieved from https://www.networkscienceinstitute.org/publications/reshaping-a-nation-mobilitycommuting-and-contact-patterns-during-the-covid-19-outbreak, 2020.

Kleinjans, Kristin J. and Arthur van Soest, "Rounding, Focal Point Answers and Nonresponse To Subjective Probability Questions," Journal of Applied Econometrics, 2014, 29 (4), $567-585$.

Lin, Rong-Gong, "6 Bay Area Counties Extend Stay-at-Home Orders through May," LA Times, 2020.

Manski, Charles F, "Measuring Expectations," Econometrica, 2004, 72 (5), 1329-1376.

McAdams, David, "Economic Epidemiology in the Wake of COVID-19," Annual Review of Economics, 2021.

Mervosh, Sarah, Denise Lu, and Vanessa Swales, "See Which States and Cities Have Told Residents to Stay at Home," The New York Times, 2020.

Miller, Grant, Áureo De Paula, and Christine Valente, "Subjective Expectations And Demand For Contraception," NBER Working Paper No. 27271, 2020.

Mueller, Andreas I., Johannes Spinnewijn, and Giorgio Topa, "Job Seekers' Perceptions and Employment Prospects: Heterogeneity, Duration Dependence, and Bias," American Economic Review, January 2021, 111 (1), 324-63.

Muñoz-Price, L Silvia, Ann B Nattinger, Frida Rivera, Ryan Hanson, Cameron G Gmehlin, Adriana Perez, Siddhartha Singh, Blake W Buchan, Nathan a Ledeboer, 
and Liliana E Pezzin, "Racial Disparities in Incidence and Outcomes Among Patients With COVID-19," JAMA Network Open, 2020, 3 (9), e2021892-e2021892.

Ngonghala, Calistus N, Enahoro Iboi, Steffen Eikenberry, Matthew Scotch, Chandini Raina MacIntyre, Matthew H Bonds, and Abba B Gumel, "Mathematical Assessment of the Impact of Non-Pharmaceutical Interventions On Curtailing the 2019 Novel Coronavirus," Mathematical Biosciences, 2020, p. 108364.

Nguyen, Thuy D, Sumedha Gupta, Martin Andersen, Ana Bento, Kosali I Simon, and Coady Wing, "Impacts of State Reopening Policy On Human Mobility," NBER Working Paper No. 27235, 2020.

Ogedegbe, Gbenga, Joseph Ravenell, Samrachana Adhikari, Mark Butler, Tiffany Cook, Fritz Francois, Eduardo Iturrate, Girardin Jean-Louis, Simon a Jones, Deborah Onakomaiya et al., "Assessment of Racial/Ethnic Disparities in Hospitalization and Mortality in Patients With COVID-19 in New York City," JAMA Network Open, 2020, 3 (12), e2026881-e2026881.

Oster, Emily, "Does Disease Cause Vaccination? Disease Outbreaks and Vaccination Response," Journal of Health Economics, 2018, 57, 90-101.

O'Driscoll, Megan, Gabriel Ribeiro Dos Santos, Lin Wang, Derek AT Cummings, Andrew S Azman, Juliette Paireau, Arnaud Fontanet, Simon Cauchemez, and Henrik Salje, "Age-Specific Mortality And Immunity Patterns Of SARS-Cov-2," Nature, 2021, 590 (7844), 140-145.

Peak, Corey M, Rebecca Kahn, Yonatan H Grad, Lauren M Childs, Ruoran Li, Marc Lipsitch, and Caroline O Buckee, "Individual Quarantine Versus Active Monitoring of Contacts For the Mitigation of COVID-19: a Modelling Study," The Lancet Infectious Diseases, 2020.

Peltzman, Sam, "The Effects of Automobile Safety Regulation," Journal of Political Economy, 1975, $83(4), 677-725$. 
Philipson, Tomas, "Economic Epidemiology and Infectious Diseases," Handbook of Health Economics, 2000, 1, 1761-1799.

Plohl, Nejc and Bojan Musil, "Modeling Compliance with COVID-19 Prevention Guidelines: the Critical Role of Trust in Science," Psychology, Health $\&$ Medicine, 2021, 26 (1), 1-12.

Polyakova, Maria, Geoffrey Kocks, Victoria Udalova, and Amy Finkelstein, "Initial Economic Damage From the COVID-19 Pandemic in the United States Is More Widespread Across Ages and Geographies Than Initial Mortality Impacts," Proceedings of the National Academy of Sciences, 2020, 117 (45), 27934-27939.

_, Victoria Udalova, Geoffrey Kocks, Katie Genadek, Keith Finlay, and Amy N. Finkelstein, "Racial Disparities in Excess All-Cause Mortality During the Early COVID-19 Pandemic Varied Substantially Across States," Health Affairs, 2021, 40 (2), 307-316. PMID: 33523748.

Prem, Kiesha, Yang Liu, Timothy W Russell, Adam J Kucharski, Rosalind M Eggo, Nicholas Davies, Stefan Flasche, Samuel Clifford, Carl AB Pearson, James D Munday et al., "The Effect of Control Strategies To Reduce Social Mixing On Outcomes of the COVID-19 Epidemic in Wuhan, China: a Modelling Study," The Lancet Public Health, 2020.

Richardson, Safiya, Jamie S Hirsch, Mangala Narasimhan, James M Crawford, Thomas McGinn, Karina W Davidson, Douglas P Barnaby, Lance B Becker, John D Chelico, Stuart L Cohen et al., "Presenting Characteristics, Comorbidities, and Outcomes Among 5700 Patients Hospitalized With COVID-19 in the New York City Area," JAMA, 2020.

Semerad, Tony, "How Utah's Coronavirus Restrictions Differ by County," The Salt Lake Tribune, https://www.sltrib.com/news/2020/04/08/utahs-six-stay-at-home, Accessed April 15, 2021, 2020.

Shavell, Steven, "On Moral Hazard and Insurance," in "Foundations of Insurance Economics," Springer, 1979, pp. 280-301. 
Spinnewijn, Johannes, "Insurance and Perceptions: How to Screen Optimists and Pessimists," The Economic Journal, 2013, 123 (569), 606-633.

Sylte, Allison, Janet Oravetz, and Caitlin Hendee, "Several Counties Rescind Stay-at-Home Orders, Adopt State Orders; Here Are Counties with Their Own Order," 9News, https://www.9news.com/article/news/health/coronavirus/colorado-cities-countiesshelter-in-place-orders/73-755635a8-4e68-49dc-8beb-60fac9325726, 2020.

Viscusi, W Kip et al., Rational Risk Policy: The 1996 Arne Ryde Memorial Lectures, Vol. 4, Oxford University Press, 1998.

Weill, Joakim A, Matthieu Stigler, Olivier Deschenes, and Michael R Springborn, "Social Distancing Responses To COVID-19 Emergency Declarations Strongly Differentiated By Income," Proceedings of the National Academy of Sciences, 2020, 117 (33), 19658-19660.

Wise, Toby, Tomislav D Zbozinek, Giorgia Michelini, Cindy C Hagan, and Dean Mobbs, "Changes in Risk Perception and Self-Reported Protective Behaviour During the First Week of the COVID-19 Pandemic in the United States," Royal Society open science, 2020, 7 (9), 200742. 


\section{Figure 1: Distribution of Beliefs about Infection Risk}

(A) When visiting a movie theater

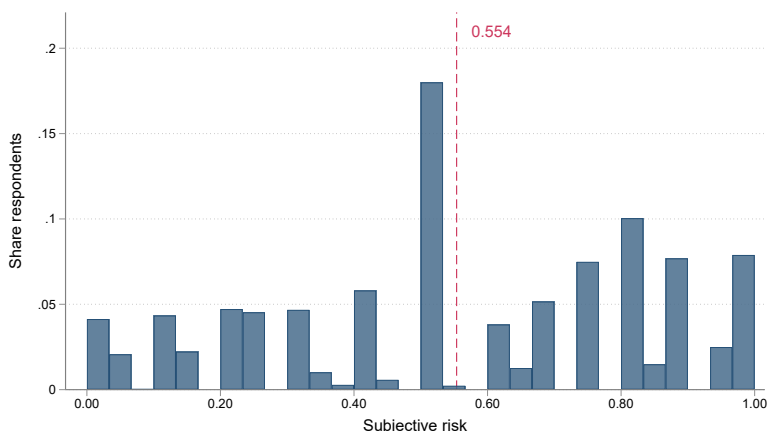

(C) When using shared transportation

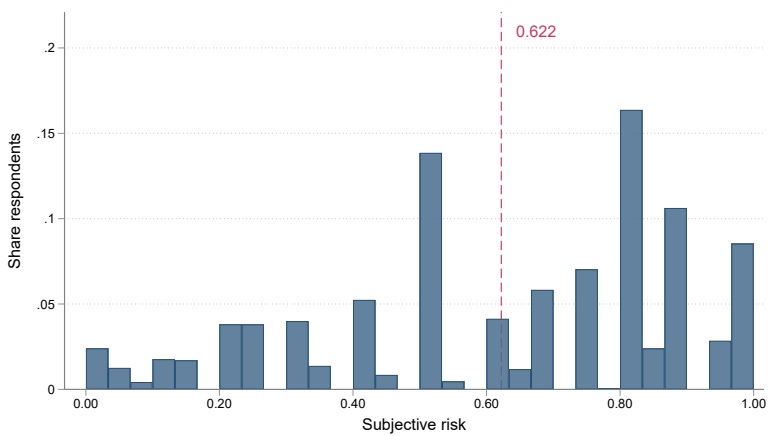

(E) When going grocery shopping

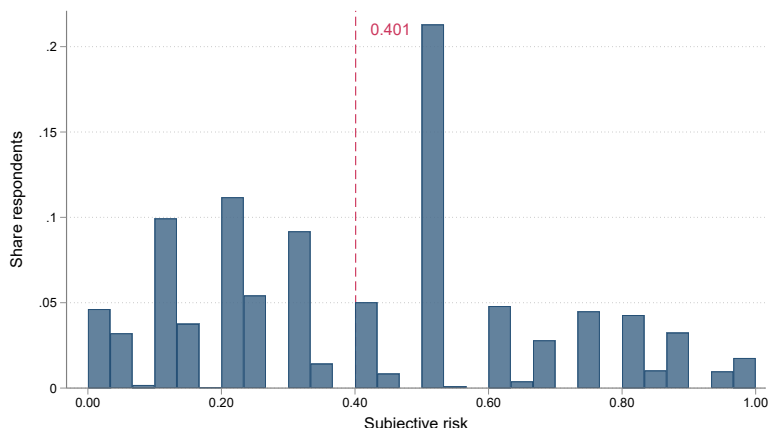

(B) When visiting a restaurant

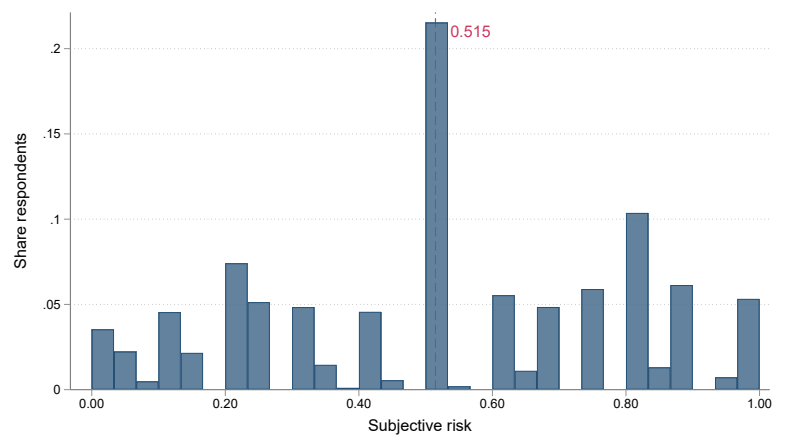

(D) When using personal services

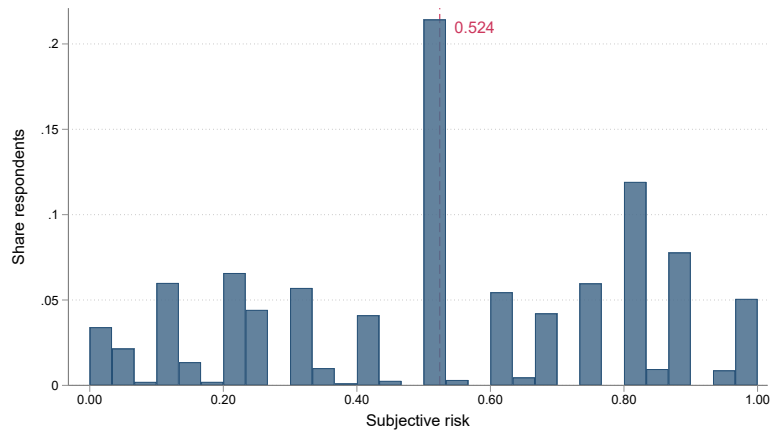

(F) Severity index

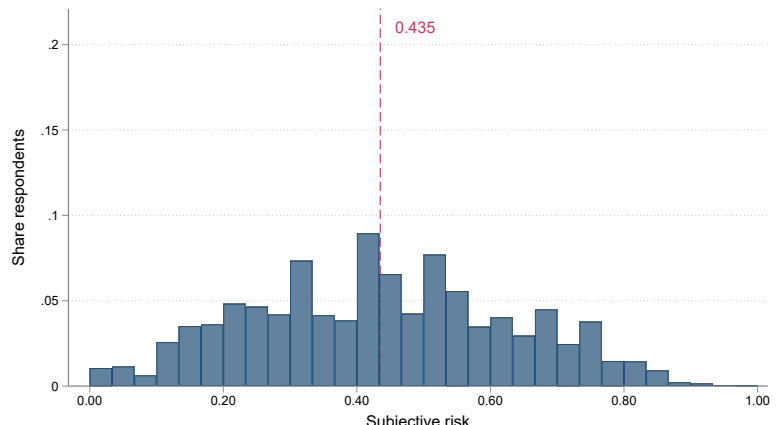

Note: The figure illustrates the distribution of beliefs about the risk of contracting COVID-19 (Panels A to E) and the risk of having a severe infection (Panel F) reported by survey respondents. The survey instrument asked respondents to state how high they estimated their chance of contracting COVID-19 when performing different economic activities on a scale from $0 \%$ to $100 \%$. The measure of severe infection in Panel $\mathrm{F}$ is an unweighted average of beliefs about the probability of having the following outcomes conditional on contracting the virus: having symptoms, needing medical care, needing hospitalization, not receiving treatment when needed, and death. The red dashed lines mark the average of belief distributions. The sample is limited to 1,127 individuals, or $92.23 \%$ of survey respondents, who self-reported that a shelter-in-place order was in effect during the time of the survey. 


\section{Figure 2: Subjective Risk Beliefs and Risk Exposure}
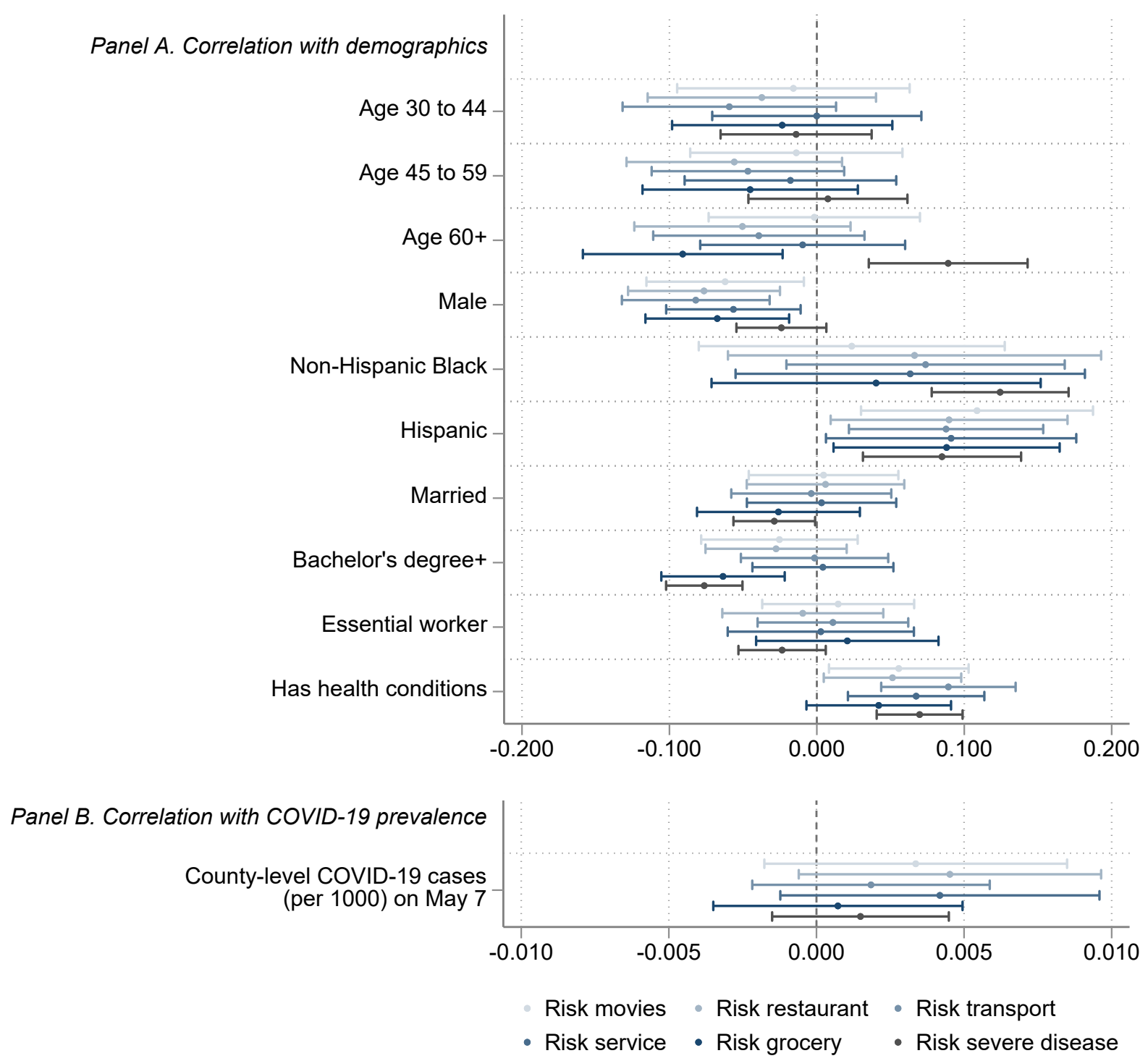

Note: The figure reports point estimates and 95\% confidence intervals from regression equations that correlate the subjective risk of contracting COVID-19 when performing different economic activities, or contracting a more severe infection, with proxies of true risk exposure. Panel A uses demographic characteristics of individuals as risk exposure proxies. Demographic characteristics were self-reported by survey participants. Panel B uses prevalence of COVID-19 in the respondent's county of residence in May 2020 as a measure of true risk exposure. Regression specification as described in Equations 1 and 2 in the main text. A separate regression is estimated for each beliefs corresponding to each economic activity (bars in shades of blue from most discretionary - movies - in the lightest shade to least discretionary - grocery - in the darkest shade) and the index of disease severity. The measure of severe infection is an unweighted average of beliefs about the probability of having the following outcomes conditional on contracting the virus: having symptoms, needing medical care, needing hospitalization, not receiving treatment when needed, and death. The sample is limited to 1,127 individuals, or $92.23 \%$ of survey respondents, who selfreported that a SIP order was in effect during the time of the survey. Survey regression weights are used to account for nonresponse. Jackknife replicate weights are used to compute standard errors. 
Figure 3: Distribution of Changes in Economic Activity

(A) Visiting a movie theater

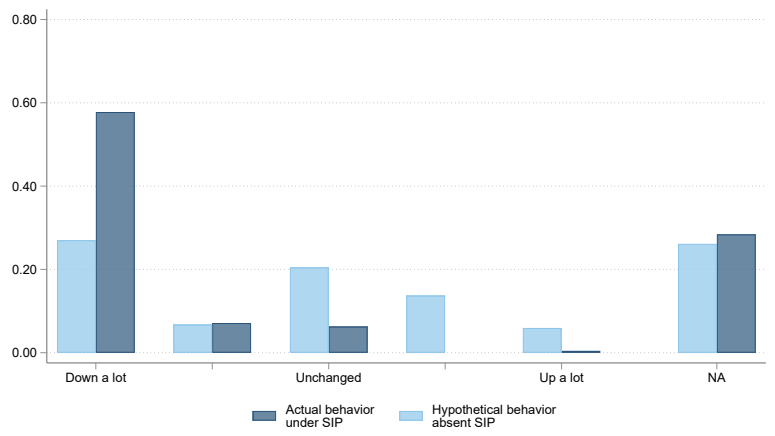

(C) Using shared transportation

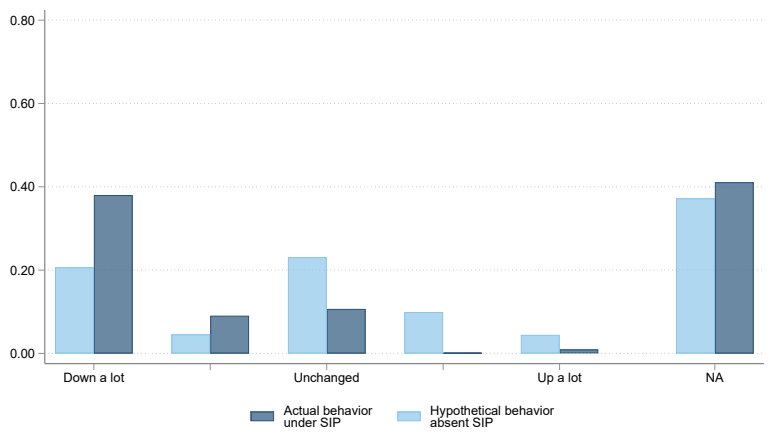

(B) Visiting a restaurant

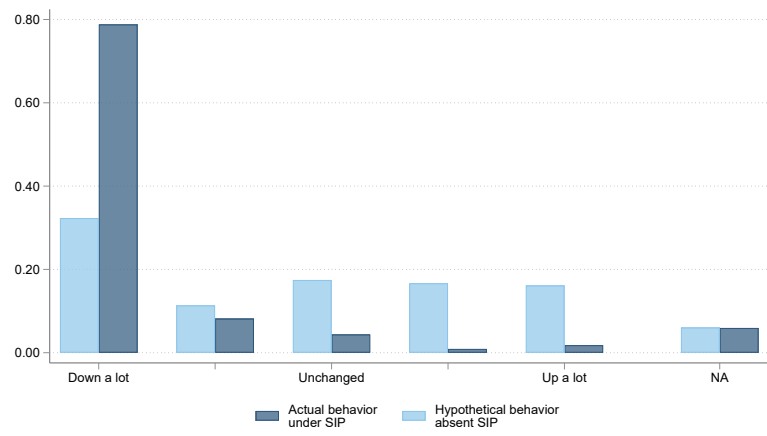

(D) Using personal services

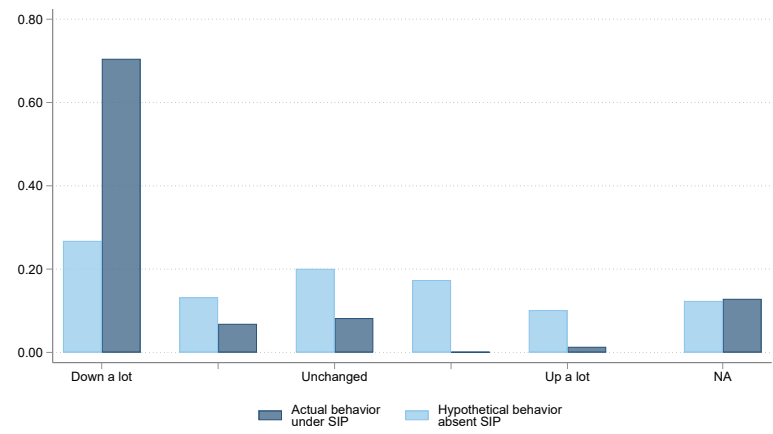

(E) Going grocery shopping

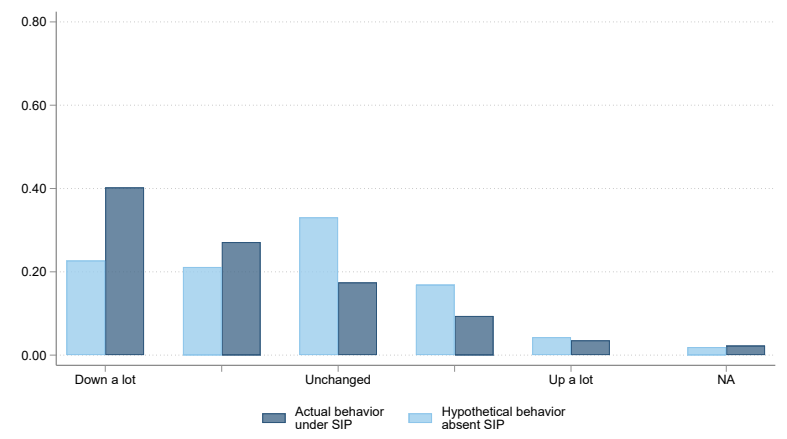

Note: The figure illustrates the distribution of self-reported changes in economic activity. For each economic activity survey participants were asked whether they decreased the activity by a lot, decreased somewhat, have not changed, increased somewhat, decreased somewhat, or spent all time at home during the pandemic and did not participate in that activity (denoted as "NA" in the figure). In each panel, the dark blue bars reflect self-reported change in behavior under existing shelter-in-place policies. The light blue bars represent hypothetical behavioral changes that individuals believe they would have undertaken in the absence of shelter-in-place orders. The sample is limited to 1,127 individuals, or $92.23 \%$ of survey respondents, who self-reported that a shelter-in-place order was in effect during the time of the survey. 
Table 1: Summary Statistics

\begin{tabular}{lcccc}
\hline & Mean & $25^{\text {th }}$ pct. & $75^{\text {th }}$ pct. & \# of obs. \\
\hline Age & 47.41 & 33.00 & 62.00 & 1,089 \\
Age: $<30$ & 0.21 & 0.00 & 0.00 & 1,089 \\
Age: $30-44$ & 0.26 & 0.00 & 1.00 & 1,089 \\
Age: $45-59$ & 0.23 & 0.00 & 0.00 & 1,089 \\
Age: $60+$ & 0.31 & 0.00 & 1.00 & 1,089 \\
Male & 0.49 & 0.00 & 1.00 & 1,118 \\
Non-Hispanic Black & 0.09 & 0.00 & 0.00 & 1,127 \\
Hispanic & 0.16 & 0.00 & 0.00 & 1,127 \\
Married & 0.53 & 0.00 & 1.00 & 1,120 \\
Bachelors degree+ & 0.31 & 0.00 & 1.00 & 1,121 \\
Essential worker & 0.28 & 0.00 & 1.00 & 1,117 \\
Have at least one chronic condition & 0.55 & 0.00 & 1.00 & 1,127 \\
County-level COVID-19 cases (per 1000) on May 7 & 3.38 & 0.86 & 3.10 & 1,127 \\
\hline
\end{tabular}

Note: Self-reported demographic characteristics of survey participants. County-level COVI-19 cases are based May 2020 records in usafacts.org. Data source is a survey sample of the U.S. population, surveyed May 7th-26th, 2020. Statistics are weighted using survey weights that correct for non-random nonresponse. The sample is limited to 1,127 individuals, or $92.23 \%$ of survey respondents, who self-reported that a SIP order was in effect during the time of the survey. 
Table 2: Reduction in Economic Activity and Subjective Probability of Infection

\begin{tabular}{|c|c|c|c|c|c|c|c|c|c|c|}
\hline & \multicolumn{2}{|c|}{ Movies } & \multicolumn{2}{|c|}{ Restaurant } & \multicolumn{2}{|c|}{ Transport } & \multicolumn{2}{|c|}{ Services } & \multicolumn{2}{|c|}{ Grocery } \\
\hline & Policy & $\begin{array}{c}\text { No } \\
\text { policy }\end{array}$ & Policy & $\begin{array}{c}\text { No } \\
\text { policy }\end{array}$ & Policy & $\begin{array}{c}\text { No } \\
\text { policy }\end{array}$ & Policy & $\begin{array}{c}\text { No } \\
\text { policy }\end{array}$ & Policy & $\begin{array}{c}\text { No } \\
\text { policy }\end{array}$ \\
\hline \multicolumn{11}{|l|}{ Subjective beliefs about risk } \\
\hline if went to movie theater & $\begin{array}{c}0.025 \\
(0.072)\end{array}$ & $\begin{array}{c}0.221^{* * *} \\
(0.072)\end{array}$ & & & & & & & & \\
\hline if went to restaurant & & & $\begin{array}{c}0.252^{* * *} \\
(0.076)\end{array}$ & $\begin{array}{c}0.425^{* * *} \\
(0.095)\end{array}$ & & & & & & \\
\hline if shared transportation & & & & & $\begin{array}{c}0.125 \\
(0.090)\end{array}$ & $\begin{array}{c}0.149^{* *} \\
(0.073)\end{array}$ & & & & \\
\hline if used personal services & & & & & & & $\begin{array}{c}0.157 \\
(0.095)\end{array}$ & $\begin{array}{c}0.397^{* * *} \\
(0.086)\end{array}$ & & \\
\hline if went to grocery & & & & & & & & & $\begin{array}{c}0.079 \\
(0.100)\end{array}$ & $\begin{array}{c}0.138 \\
(0.087)\end{array}$ \\
\hline Mean of Dep. Var. & 0.58 & 0.27 & 0.79 & 0.32 & 0.38 & 0.21 & 0.71 & 0.27 & 0.40 & 0.23 \\
\hline Std. Dev. of Dep. Var. & 0.49 & 0.44 & 0.41 & 0.47 & 0.49 & 0.40 & 0.45 & 0.45 & 0.49 & 0.42 \\
\hline No. of Obs. & 1,102 & 1,099 & 1,110 & 1,108 & 1,111 & 1,104 & 1,109 & 1,111 & 1,105 & 1,109 \\
\hline Beliefs elasticity & 0.02 & 0.45 & 0.16 & 0.68 & 0.20 & 0.44 & 0.12 & 0.77 & 0.08 & 0.24 \\
\hline
\end{tabular}

Note: Table presents the results of 10 separate linear probability models as specified in Equation 3 . The dependent variable is an indicator of whether the respondent decreased the economic activity by a lot. We estimate a separate model for actual self-reported change in behavior ("policy") and self-reported change behavior in the hypothetical without SIP policies ("no policy"). The independent variables include subjective beliefs of behaviorspecific risks, as well as the index of subjective severity beliefs. The measure of severe infection is an unweighted average of beliefs about the probability of having the following outcomes conditional on contracting the virus: having symptoms, needing medical care, needing hospitalization, not receiving treatment when needed, and death. Models also include the risk of staying at home and the number days since the SIP order had been enacted. The sample is limited to 1,127 individuals, or $92.23 \%$ of survey respondents, who self-reported that a SIP order was in effect during the time of the survey. Survey regression weights are used to account for nonresponse. Stanford errors using jackknife replicate weights are reported in parentheses. $*$ for $p<.1 * *$ for $p<.05$ and $* * *$ for $p<.01$. 
Table 3: Reduction in Economic Activity and Geographic Prevalence of COVID-19

\begin{tabular}{|c|c|c|c|c|c|c|c|c|c|c|}
\hline & \multicolumn{2}{|c|}{ Movies } & \multicolumn{2}{|c|}{ Restaurant } & \multicolumn{2}{|c|}{ Transport } & \multicolumn{2}{|c|}{ Services } & \multicolumn{2}{|c|}{ Grocery } \\
\hline & Policy & $\begin{array}{c}\text { No } \\
\text { policy }\end{array}$ & Policy & $\begin{array}{c}\text { No } \\
\text { policy }\end{array}$ & Policy & $\begin{array}{c}\text { No } \\
\text { policy }\end{array}$ & Policy & $\begin{array}{c}\text { No } \\
\text { policy }\end{array}$ & Policy & $\begin{array}{c}\text { No } \\
\text { policy }\end{array}$ \\
\hline $\begin{array}{l}\text { County-level COVID-19 cases } \\
\text { (per 1000) on May } 7\end{array}$ & $\begin{array}{c}0.006 \\
(0.004)\end{array}$ & $\begin{array}{c}0.011^{* * *} \\
(0.004)\end{array}$ & $\begin{array}{l}0.006^{*} \\
(0.003)\end{array}$ & $\begin{array}{l}0.010^{* *} \\
(0.004)\end{array}$ & $\begin{array}{c}0.019^{* * *} \\
(0.005)\end{array}$ & $\begin{array}{c}0.013^{* * *} \\
(0.004)\end{array}$ & $\begin{array}{l}0.010^{* *} \\
(0.004)\end{array}$ & $\begin{array}{l}0.009^{* *} \\
(0.004)\end{array}$ & $\begin{array}{c}0.003 \\
(0.005)\end{array}$ & $\begin{array}{l}0.011^{* *} \\
(0.004)\end{array}$ \\
\hline $\begin{array}{l}\text { Mean of Dep. Var. } \\
\text { Std. Dev. of Dep. Var. } \\
\text { No. of Obs. }\end{array}$ & $\begin{array}{c}0.58 \\
0.49 \\
1,118\end{array}$ & $\begin{array}{c}0.27 \\
0.44 \\
1,115\end{array}$ & $\begin{array}{l}0.79 \\
0.41 \\
1,120\end{array}$ & $\begin{array}{l}0.32 \\
0.47 \\
1,118\end{array}$ & $\begin{array}{c}0.38 \\
0.49 \\
1,127\end{array}$ & $\begin{array}{c}0.21 \\
0.41 \\
1,120\end{array}$ & $\begin{array}{l}0.71 \\
0.46 \\
1,120\end{array}$ & $\begin{array}{l}0.27 \\
0.44 \\
1,122\end{array}$ & $\begin{array}{l}0.40 \\
0.49 \\
1,118\end{array}$ & $\begin{array}{c}0.23 \\
0.42 \\
1,122\end{array}$ \\
\hline Prevalence elasticity & 0.03 & 0.14 & 0.03 & 0.11 & 0.17 & 0.21 & 0.05 & 0.11 & 0.03 & 0.16 \\
\hline
\end{tabular}

Note: Table presents the results of 10 separate linear regressions. The dependent variable is an indicator of whether the respondent decreased the activity by a lot with a separate model for actual behavior and hypothetical behavior in the absence of SIP. The independent variable is the prevalence of COVID-19 cases in May 2020. The sample is limited to 1,127 individuals, or $92.23 \%$ of survey respondents, who self-reported that a SIP order was in effect during the time of the survey. Survey regression weights are used to account for nonresponse. Stanford errors using jackknife replicate weights are reported in parentheses. ${ }^{*}$ for $p<.1 * *$ for $p<.05$ and ${ }^{* * *}$ for $p<.01$. 


\section{A Appendix}

\section{A.1 Survey weights}

Throughout the analysis we used survey weights to account for non-random nonresponse based on observable demographics.

The computation of the survey weights began with the base weights, which were then adjusted for differential nonresponse to the survey request and to within-household selection, and then calibrated to external totals. The base weight is the reciprocal of the probability of selection of the address. The adjustment for nonresponse used a weighting class adjustment to redistribute base weights of eligible nonrespondents to eligible respondents within the same weighting class, after accounting for the estimated proportion of cases with undetermined eligibility that are eligible; the weighting classes were defined using address-level variables available on the sampling frame and census tract-level characteristics from the American Community Survey (ACS; 2018 5-year tables). Candidate variables included an indicator of whether a name could be matched to the address, the dwelling type (multi-unit structure or not), census region, indicators (from USPS files) of whether the address is vacant and whether the address is seasonal, and quartiles of the following census tract-level characteristics: percent below poverty, percent with less than a high school diploma, percent with a college degree or higher, percent age $65+$, percent Black, and percent Hispanic. A classification tree algorithm was used to identify the classes, with survey response status as the variable being modeled.

Next, the nonresponse adjusted weights were adjusted to account for the selection of one adult among the adults in the household. The adjustment factor is the number of adults in the household.

Finally, the adjusted weights were raked to population estimates from the ACS (2018; 1-year tables). This raking adjustment aligns estimated totals from the survey to the ACS estimates on the following dimensions: (1) Sex by age category (18-29, 30-49, 50-69, 70+); (2) Race (White alone, Black alone, other) of persons age 18 or older, by census region; and (3) Ethnicity (Hispanic, non-Hispanic) of persons age 18 or older, by census region.

For computing basic descriptive statistic point estimates, the survey weights themselves are 
sufficient to account for the complex sample design. But for estimating the precision of those estimates (e.g., producing standard errors and confidence intervals), it is necessary to use a method that takes into account the precision effects of the complex sampling and estimation procedures used in this study. The method we used was to compute replicate weights using the unstratified "delete one group" jackknife with 80 random groups. We constructed the replicates by randomly sorting the sampled addresses into 80 groups and then deleting one group at a time, to result in 80 replicates. For each replicate, a set of replicate base weights is produced by first assigning a replicate weight multiplier of 0 to the addresses that were deleted in constructing the replicate and assigning a replicate weight multiplier of $80 / 79$ to the addresses that were not deleted in constructing the replicate, then multiplying the full-sample address base weight by the replicate weight multiplier. Each set of replicate weights underwent the same set of adjustments that were applied to the full-sample weights. 


\section{A.2 Survey questionnaire}

\section{(1) Questions about Behavioral Changes}

How has the time you spend on each of the following activities changed since the pandemic?

\section{Q3A Going to the grocery store}

1. Decreased a lot (by more than $50 \%$ )

2. Decreased somewhat (by less than $50 \%$ )

3. Has not changed

4. Increased somewhat (by less than 50\%)

5. Increased a lot (by more than 50\%)

6. I didn't do this before the pandemic

Q3B Receive personal services such as haircuts or manicures, or go to the gym

1. Decreased a lot (by more than $50 \%$ )

2. Decreased somewhat (by less than 50\%)

3. Has not changed

4. Increased somewhat (by less than $50 \%$ )

5. Increased a lot (by more than 50\%)

6. I didn't do this before the pandemic

\section{Q3C Exercise outdoors}

1. Decreased a lot (by more than $50 \%$ )

2. Decreased somewhat (by less than $50 \%$ )

3. Has not changed 
4. Increased somewhat (by less than 50\%)

5. Increased a lot (by more than 50\%)

6. I didn't do this before the pandemic

\section{Q3D Eat in a restaurant (not including take out or delivery)}

1. Decreased a lot (by more than $50 \%$ )

2. Decreased somewhat (by less than $50 \%$ )

3. Has not changed

4. Increased somewhat (by less than $50 \%$ )

5. Increased a lot (by more than 50\%)

6. I didn't do this before the pandemic

\section{Q3F See a movie in a theater}

1. Decreased a lot (by more than 50\%)

2. Decreased somewhat (by less than 50\%)

3. Has not changed

4. Increased somewhat (by less than $50 \%$ )

5. Increased a lot (by more than 50\%)

6. I didn't do this before the pandemic

Q3G Use shared transportation (such as commercial flights, trains, buses, or shared ride services)

1. Decreased a lot (by more than $50 \%$ )

2. Decreased somewhat (by less than $50 \%$ ) 
3. Has not changed

4. Increased somewhat (by less than 50\%)

5. Increased a lot (by more than 50\%)

6. I didn't do this before the pandemic

\section{(2) Elicitation of Subjective Beliefs about Risk}

The next questions ask about the chances of you or someone like you catching the coronavirus.

Q10 How likely is it that you or someone like you would catch the coronavirus if you stayed at home the vast majority of the time? (Percentage 0-100)

0 (No chance) - 100 (Sure to happen)

Q11 How likely is it that you or someone like you would catch the coronavirus if you received personal services, such as haircuts or manicures, or went to the gym?

0 (No chance) - 100 (Sure to happen)

Q12 How likely is it that you or someone like you would catch the coronavirus if you exercised outdoors?

0 (No chance) - 100 (Sure to happen)

Q13 How likely is it that you or someone like you would catch the coronavirus if you went to the grocery store?

0 (No chance) - 100 (Sure to happen)

Q14 How likely is it that you or someone like you would catch the coronavirus if you ate at a restaurant, not including take out or delivery?

0 (No chance) - 100 (Sure to happen)

Q15 How likely is it that you or someone like you would catch the coronavirus if you went to work regularly outside your home? 
0 (No chance) - 100 (Sure to happen)

Q16 How likely is it that you or someone like you would catch the coronavirus if you saw a movie in a theater?

0 (No chance) - 100 (Sure to happen)

Q17 How likely is it that you or someone like you would catch the coronavirus if you used shared transportation, such as commercial flights, trains, buses, or shared ride services?

0 (No chance) - 100 (Sure to happen)

The next questions ask about what would happen if you or somebody like you caught the coronavirus.

Q18 If you or somebody like you caught the coronavirus, how likely is it that you would not have any symptoms?

0 (No chance) - 100 (Sure to happen)

Q19 If you or somebody like you caught the coronavirus, how likely is it that you would need medical care?

0 (No chance) - 100 (Sure to happen)

Q20 If you or somebody like you caught the coronavirus, how likely is it that you would need to be hospitalized?

0 (No chance) - 100 (Sure to happen)

Q21 If you or somebody like you caught the coronavirus, how likely is it that you would die?

0 (No chance) - 100 (Sure to happen)

Q22 If you or somebody like you caught the coronavirus, how likely is it that the hospital would have the staff and supplies to treat you?

0 (No chance) - 100 (Sure to happen) 
Table A.1: Subjective Risk Beliefs and Risk Exposure

\begin{tabular}{|c|c|c|c|c|c|c|}
\hline & Movie & Restaurant & Transport & Service & Grocery & $\begin{array}{c}\text { Severity } \\
\text { index }\end{array}$ \\
\hline \multicolumn{7}{|c|}{ Panel A. Correlation with demographics } \\
\hline Age 30 to 44 & $\begin{array}{l}-0.016 \\
(0.040)\end{array}$ & $\begin{array}{l}-0.037 \\
(0.039)\end{array}$ & $\begin{array}{l}-0.059 \\
(0.036)\end{array}$ & $\begin{array}{l}-0.000 \\
(0.036)\end{array}$ & $\begin{array}{l}-0.023 \\
(0.038)\end{array}$ & $\begin{array}{l}-0.014 \\
(0.026)\end{array}$ \\
\hline Age 45 to 59 & $\begin{array}{l}-0.014 \\
(0.036)\end{array}$ & $\begin{array}{l}-0.056 \\
(0.037)\end{array}$ & $\begin{array}{l}-0.047 \\
(0.033)\end{array}$ & $\begin{array}{l}-0.018 \\
(0.036)\end{array}$ & $\begin{array}{l}-0.045 \\
(0.037)\end{array}$ & $\begin{array}{c}0.008 \\
(0.027)\end{array}$ \\
\hline Age $60+$ & $\begin{array}{l}-0.002 \\
(0.036)\end{array}$ & $\begin{array}{l}-0.050 \\
(0.037)\end{array}$ & $\begin{array}{l}-0.039 \\
(0.036)\end{array}$ & $\begin{array}{l}-0.010 \\
(0.035)\end{array}$ & $\begin{array}{c}-0.091^{* * *} \\
(0.034)\end{array}$ & $\begin{array}{c}0.089^{* * *} \\
(0.027)\end{array}$ \\
\hline Male & $\begin{array}{c}-0.062^{* *} \\
(0.027)\end{array}$ & $\begin{array}{c}-0.077^{* * *} \\
(0.026)\end{array}$ & $\begin{array}{l}-0.082^{* * *} \\
(0.025)\end{array}$ & $\begin{array}{c}-0.057^{* *} \\
(0.023)\end{array}$ & $\begin{array}{l}-0.068^{* * *} \\
(0.024)\end{array}$ & $\begin{array}{l}-0.024 \\
(0.015)\end{array}$ \\
\hline Non-Hispanic Black & $\begin{array}{c}0.024 \\
(0.052)\end{array}$ & $\begin{array}{c}0.066 \\
(0.064)\end{array}$ & $\begin{array}{c}0.074 \\
(0.047)\end{array}$ & $\begin{array}{c}0.063 \\
(0.060)\end{array}$ & $\begin{array}{c}0.040 \\
(0.056)\end{array}$ & $\begin{array}{c}0.124^{* * *} \\
(0.023)\end{array}$ \\
\hline Hispanic & $\begin{array}{c}0.109^{* * *} \\
(0.040)\end{array}$ & $\begin{array}{l}0.090^{* *} \\
(0.040)\end{array}$ & $\begin{array}{c}0.088^{* * *} \\
(0.033)\end{array}$ & $\begin{array}{l}0.091^{* *} \\
(0.043)\end{array}$ & $\begin{array}{l}0.088^{* *} \\
(0.039)\end{array}$ & $\begin{array}{c}0.085^{* * *} \\
(0.027)\end{array}$ \\
\hline Married & $\begin{array}{c}0.005 \\
(0.025)\end{array}$ & $\begin{array}{c}0.006 \\
(0.027)\end{array}$ & $\begin{array}{l}-0.004 \\
(0.027)\end{array}$ & $\begin{array}{c}0.003 \\
(0.025)\end{array}$ & $\begin{array}{l}-0.026 \\
(0.028)\end{array}$ & $\begin{array}{c}-0.029^{* *} \\
(0.014)\end{array}$ \\
\hline Bachelor's degree+ & $\begin{array}{l}-0.025 \\
(0.027)\end{array}$ & $\begin{array}{l}-0.028 \\
(0.024)\end{array}$ & $\begin{array}{l}-0.002 \\
(0.025)\end{array}$ & $\begin{array}{c}0.004 \\
(0.024)\end{array}$ & $\begin{array}{c}-0.064^{* * *} \\
(0.021)\end{array}$ & $\begin{array}{c}-0.076^{* * *} \\
(0.013)\end{array}$ \\
\hline Essential worker & $\begin{array}{c}0.014 \\
(0.026)\end{array}$ & $\begin{array}{l}-0.010 \\
(0.027)\end{array}$ & $\begin{array}{c}0.011 \\
(0.026)\end{array}$ & $\begin{array}{c}0.003 \\
(0.032)\end{array}$ & $\begin{array}{c}0.021 \\
(0.031)\end{array}$ & $\begin{array}{l}-0.024 \\
(0.015)\end{array}$ \\
\hline Has health conditions & $\begin{array}{l}0.056^{* *} \\
(0.024)\end{array}$ & $\begin{array}{l}0.051^{* *} \\
(0.023)\end{array}$ & $\begin{array}{c}0.089^{* * *} \\
(0.023)\end{array}$ & $\begin{array}{c}0.067^{* * *} \\
(0.023)\end{array}$ & $\begin{array}{l}0.042^{*} \\
(0.025)\end{array}$ & $\begin{array}{c}0.070^{* * *} \\
(0.015)\end{array}$ \\
\hline $\begin{array}{l}\text { Mean of Dep. Var. } \\
\text { Std. Dev. of Dep. Var. } \\
\text { No. of Obs. }\end{array}$ & $\begin{array}{c}0.56 \\
0.29 \\
1,065\end{array}$ & $\begin{array}{c}0.52 \\
0.28 \\
1,069\end{array}$ & $\begin{array}{c}0.62 \\
0.28 \\
1,065\end{array}$ & $\begin{array}{c}0.53 \\
0.28 \\
1,068\end{array}$ & $\begin{array}{c}0.40 \\
0.26 \\
1,066\end{array}$ & $\begin{array}{c}0.44 \\
0.19 \\
1,074\end{array}$ \\
\hline \multicolumn{7}{|c|}{ Panel B. Correlation with COVID-19 prevalence } \\
\hline $\begin{array}{l}\text { County-level COVID-19 cases } \\
\text { (per 1000) on May } 7\end{array}$ & $\begin{array}{c}0.003 \\
(0.003)\end{array}$ & $\begin{array}{l}0.005^{*} \\
(0.003)\end{array}$ & $\begin{array}{c}0.002 \\
(0.002)\end{array}$ & $\begin{array}{c}0.004 \\
(0.003)\end{array}$ & $\begin{array}{c}0.001 \\
(0.002)\end{array}$ & $\begin{array}{c}0.001 \\
(0.002)\end{array}$ \\
\hline $\begin{array}{l}\text { Mean of Dep. Var. } \\
\text { Std. Dev. of Dep. Var. } \\
\text { No. of Obs. }\end{array}$ & $\begin{array}{c}0.55 \\
0.29 \\
1,113\end{array}$ & $\begin{array}{c}0.51 \\
0.28 \\
1,120\end{array}$ & $\begin{array}{c}0.62 \\
0.28 \\
1,115\end{array}$ & $\begin{array}{c}0.52 \\
0.28 \\
1,119\end{array}$ & $\begin{array}{c}0.40 \\
0.26 \\
1,117\end{array}$ & $\begin{array}{c}0.43 \\
0.20 \\
1,124\end{array}$ \\
\hline
\end{tabular}

Note: Table presents the results of 12 separate OLS regressions specified in Equations 1 and 2. The point estimates are reported graphically in Figure 2. The dependent variables are the subjective belief about the risk of contracting COVID-19 when performing different economic activities or the severity of the disease conditional on contracting the virus. The measure of severe infection is an unweighted average of beliefs about the probability of having the following outcomes conditional on contracting the virus: having symptoms, needing medical care, needing hospitalization, not receiving treatment when needed, and death. All regression control for the number of days since a SIP order had been enacted. The sample is limited to 1,127 individuals, or $92.23 \%$ of survey respondents, who self-reported that a SIP order was in effect during the time of the survey. Survey regression weights are used to account for nonresponse. Stanford errors using jackknife replicate weights are reported in parentheses. ${ }^{*}$ for $p<.1 * *$ for $p<.05$ and $* * *$ for $p<.01$. 
Table A.2: Reduction in Economic Activity and Subjective Probability of Infection

\begin{tabular}{|c|c|c|c|c|c|c|c|c|c|c|}
\hline & \multicolumn{2}{|c|}{ Movies } & \multicolumn{2}{|c|}{ Restaurant } & \multicolumn{2}{|c|}{ Transport } & \multicolumn{2}{|c|}{ Services } & \multicolumn{2}{|c|}{ Grocery } \\
\hline & Policy & $\begin{array}{c}\text { No } \\
\text { policy }\end{array}$ & Policy & $\begin{array}{c}\text { No } \\
\text { policy }\end{array}$ & Policy & $\begin{array}{c}\text { No } \\
\text { policy }\end{array}$ & Policy & $\begin{array}{c}\text { No } \\
\text { policy }\end{array}$ & Policy & $\begin{array}{c}\text { No } \\
\text { policy }\end{array}$ \\
\hline \multicolumn{11}{|l|}{$\begin{array}{l}\text { Subjective beliefs about risk } \\
\text { if went to movie theater }\end{array}$} \\
\hline predict "increased a lot" & $\begin{array}{l}-0.000 \\
(0.001)\end{array}$ & $\begin{array}{c}-0.055^{* * *} \\
(0.019)\end{array}$ & & & & & & & & \\
\hline predict "increased somewhat" & & $\begin{array}{c}-0.104^{* * *} \\
(0.037)\end{array}$ & & & & & & & & \\
\hline predict "unchanged" & $\begin{array}{l}-0.020 \\
(0.065)\end{array}$ & $\begin{array}{c}-0.065^{* *} \\
(0.026)\end{array}$ & & & & & & & & \\
\hline predict "decreased somewhat" & $\begin{array}{c}-0.002 \\
(0.005)\end{array}$ & $\begin{array}{l}0.027^{* *} \\
(0.011)\end{array}$ & & & & & & & & \\
\hline predict "decreased a lot" & $\begin{array}{c}0.022 \\
(0.072)\end{array}$ & $\begin{array}{c}0.197^{* * *} \\
(0.064)\end{array}$ & & & & & & & & \\
\hline predict "unchanged" & & & $\begin{array}{c}-0.136^{* * *} \\
(0.041)\end{array}$ & $\begin{array}{c}-0.032^{*} \\
(0.018)\end{array}$ & & & & & & \\
\hline predict "decreased somewhat" & & & $\begin{array}{c}-0.090^{* * *} \\
(0.032)\end{array}$ & $\begin{array}{l}0.030^{* *} \\
(0.012)\end{array}$ & & & & & & \\
\hline predict "decreased a lot" & & & $\begin{array}{c}0.262^{* * *} \\
(0.078)\end{array}$ & $\begin{array}{c}0.241^{* * *} \\
(0.085)\end{array}$ & & & & & & \\
\hline
\end{tabular}




\begin{tabular}{|c|c|c|c|c|c|c|c|c|c|c|}
\hline \multirow{2}{*}{ (Cont'd.) } & \multicolumn{2}{|c|}{ Movies } & \multicolumn{2}{|c|}{ Restaurant } & \multicolumn{2}{|c|}{ Transport } & \multicolumn{2}{|c|}{ Services } & \multicolumn{2}{|c|}{ Grocery } \\
\hline & Policy & $\begin{array}{c}\text { No } \\
\text { policy }\end{array}$ & Policy & $\begin{array}{c}\text { No } \\
\text { policy }\end{array}$ & Policy & $\begin{array}{c}\text { No } \\
\text { policy }\end{array}$ & Policy & $\begin{array}{c}\text { No } \\
\text { policy }\end{array}$ & Policy & $\begin{array}{c}\text { No } \\
\text { policy }\end{array}$ \\
\hline \multicolumn{11}{|l|}{ if shared transportation } \\
\hline predict "increased a lot" & & & & & $\begin{array}{l}-0.003 \\
(0.004)\end{array}$ & $\begin{array}{c}-0.028^{* *} \\
(0.013)\end{array}$ & & & & \\
\hline predict "increased somewhat" & & & & & $\begin{array}{l}-0.001 \\
(0.001)\end{array}$ & $\begin{array}{c}-0.055^{*} \\
(0.028)\end{array}$ & & & & \\
\hline predict "unchanged" & & & & & $\begin{array}{l}-0.082 \\
(0.087)\end{array}$ & $\begin{array}{l}-0.044 \\
(0.027)\end{array}$ & & & & \\
\hline predict "decreased somewhat" & & & & & $\begin{array}{c}0.004 \\
(0.005)\end{array}$ & $\begin{array}{l}0.017^{*} \\
(0.009)\end{array}$ & & & & \\
\hline predict "decreased a lot" & & & & & $\begin{array}{c}0.081 \\
(0.086)\end{array}$ & $\begin{array}{l}0.110^{*} \\
(0.056)\end{array}$ & & & & \\
\hline
\end{tabular}

\section{if used personal services}

predict "increased a lot"

predict "increased somewhat"

predict "unchanged"

predict "decreased somewhat"

predict "decreased a lot"
$-0.009-0.118^{* * *}$

(0.007) (0.028)

$-0.001-0.154^{* * *}$

(0.001) (0.041)

$-0.109-0.068^{* *}$

$(0.076) \quad(0.028)$
-0.024

$-0.024 \quad 0.064^{* * *}$

(0.018) (0.018)

$0.1440 .276^{* * *}$

(0.100) (0.073) 


\begin{tabular}{|c|c|c|c|c|c|c|c|c|c|c|}
\hline \multirow{2}{*}{ (Cont'd.) } & \multicolumn{2}{|c|}{ Movies } & \multicolumn{2}{|c|}{ Restaurant } & \multicolumn{2}{|c|}{ Transport } & \multicolumn{2}{|c|}{ Services } & \multicolumn{2}{|c|}{ Grocery } \\
\hline & Policy & $\begin{array}{c}\text { No } \\
\text { policy }\end{array}$ & Policy & $\begin{array}{c}\text { No } \\
\text { policy }\end{array}$ & Policy & $\begin{array}{c}\text { No } \\
\text { policy }\end{array}$ & Policy & $\begin{array}{c}\text { No } \\
\text { policy }\end{array}$ & Policy & $\begin{array}{c}\text { No } \\
\text { policy }\end{array}$ \\
\hline \multicolumn{11}{|l|}{ if went to grocery } \\
\hline predict "increased a lot" & & & & & & & & & $\begin{array}{l}-0.012 \\
(0.013)\end{array}$ & $\begin{array}{l}-0.010 \\
(0.013)\end{array}$ \\
\hline predict "increased somewhat" & & & & & & & & & $\begin{array}{l}-0.028 \\
(0.029)\end{array}$ & $\begin{array}{l}-0.032 \\
(0.045)\end{array}$ \\
\hline predict "unchanged" & & & & & & & & & $\begin{array}{l}-0.041 \\
(0.046)\end{array}$ & $\begin{array}{l}-0.021 \\
(0.030)\end{array}$ \\
\hline predict "decreased somewhat" & & & & & & & & & $\begin{array}{l}-0.009 \\
(0.011)\end{array}$ & $\begin{array}{c}0.018 \\
(0.025)\end{array}$ \\
\hline predict "decreased a lot" & & & & & & & & & $\begin{array}{c}0.090 \\
(0.098)\end{array}$ & $\begin{array}{c}0.045 \\
(0.064)\end{array}$ \\
\hline
\end{tabular}

\section{COVID-19 disease (index)}

\begin{tabular}{|c|c|c|c|c|c|c|c|c|c|c|}
\hline edi & $\begin{array}{c}0.006 \\
(0.007)\end{array}$ & $(0.02$ & & $\begin{array}{l}-0.069 \\
(0.059)\end{array}$ & $\begin{array}{r}0.0 \\
(0.0\end{array}$ & $\begin{array}{l}-0.001 \\
(0.021)\end{array}$ & $\begin{array}{c}0.009 \\
(0.008)\end{array}$ & $\begin{array}{c}-0.086^{* *} \\
(0.037)\end{array}$ & $\begin{array}{c}-0.043^{* * *} \\
(0.015)\end{array}$ & $\begin{array}{l}4^{* *} \\
7)\end{array}$ \\
\hline predict" & & & & & & & $\begin{array}{c}0.001 \\
(0.001)\end{array}$ & & & \\
\hline predict " $u$ & $\begin{array}{l}0.290^{* *} \\
(0.111)\end{array}$ & & $\begin{array}{c}0.175^{* * *} \\
(0.052)\end{array}$ & & & & & & $\begin{array}{c}-0.143^{* * *} \\
(0.048)\end{array}$ & \\
\hline pred & $\begin{array}{l}0.022^{* *} \\
(0.009)\end{array}$ & & $\begin{array}{c}0.116^{* * *} \\
(0.038)\end{array}$ & [3) & $\begin{array}{l}-0.003 \\
(0.007)\end{array}$ & $\begin{array}{c}0.000 \\
(0.013)\end{array}$ & $\begin{array}{c}0.024 \\
(0.017)\end{array}$ & & & \\
\hline predi & $\begin{array}{c}-0.318^{* *} \\
(0.121) \\
\end{array}$ & $\begin{array}{c}0.049 \\
(0.090) \\
\end{array}$ & $\begin{array}{c}-0.336^{* * *} \\
(0.098) \\
\end{array}$ & 16 & & $\begin{array}{c}0.002 \\
(0.081) \\
\end{array}$ & $\begin{array}{l}-0.139 \\
(0.101) \\
\end{array}$ & & $\begin{array}{c}0.315^{* * *} \\
(0.102) \\
\end{array}$ & \\
\hline $\begin{array}{l}\text { Std. Dev. of Dep. Var. } \\
\text { No. of Obs. }\end{array}$ & $\begin{array}{c}1.78 \\
0.96 \\
1,102\end{array}$ & & & & & & & & & $\begin{array}{c}2.58 \\
1.14 \\
1,109\end{array}$ \\
\hline
\end{tabular}

Note: Table reports the result of re-estimating the models in Table 2 of the main manuscript using an ordered logit instead of a linear probability model. 
Table A.3: Reduction in Economic Activity and Subjective Probability of Infection

\begin{tabular}{|c|c|c|c|c|c|c|c|c|c|c|}
\hline & \multicolumn{2}{|c|}{ Movies } & \multicolumn{2}{|c|}{ Restaurant } & \multicolumn{2}{|c|}{ Transport } & \multicolumn{2}{|c|}{ Services } & \multicolumn{2}{|c|}{ Grocery } \\
\hline & Policy & $\begin{array}{c}\text { No } \\
\text { policy }\end{array}$ & Policy & $\begin{array}{c}\text { No } \\
\text { policy }\end{array}$ & Policy & $\begin{array}{c}\mathrm{No} \\
\text { policy }\end{array}$ & Policy & $\begin{array}{c}\text { No } \\
\text { policy }\end{array}$ & Policy & $\begin{array}{c}\text { No } \\
\text { policy }\end{array}$ \\
\hline \multicolumn{11}{|l|}{ Subjective beliefs about risk } \\
\hline if went to movie theater & $\begin{array}{c}0.077 \\
(0.081)\end{array}$ & $\begin{array}{c}0.339^{* * *} \\
(0.096)\end{array}$ & & & & & & & & \\
\hline if went to restaurant & & & $\begin{array}{c}0.264^{* * *} \\
(0.075)\end{array}$ & $\begin{array}{c}0.437^{* * *} \\
(0.101)\end{array}$ & & & & & & \\
\hline if shared transportation & & & & & $\begin{array}{c}0.330^{* * *} \\
(0.112)\end{array}$ & $\begin{array}{l}0.295^{* *} \\
(0.112)\end{array}$ & & & & \\
\hline if used personal services & & & & & & & $\begin{array}{l}0.182^{* *} \\
(0.085)\end{array}$ & $\begin{array}{c}0.470^{* * *} \\
(0.093)\end{array}$ & & \\
\hline if went to grocery & & & & & & & & & $\begin{array}{c}0.082 \\
(0.102)\end{array}$ & $\begin{array}{c}0.142 \\
(0.089)\end{array}$ \\
\hline of more severe COVID-19 disease (index) & $\begin{array}{l}-0.124 \\
(0.124)\end{array}$ & $\begin{array}{c}0.073 \\
(0.143)\end{array}$ & $\begin{array}{c}-0.251^{* *} \\
(0.097)\end{array}$ & $\begin{array}{c}0.058 \\
(0.119)\end{array}$ & $\begin{array}{c}0.094 \\
(0.151)\end{array}$ & $\begin{array}{c}0.073 \\
(0.151)\end{array}$ & $\begin{array}{l}-0.009 \\
(0.106)\end{array}$ & $\begin{array}{c}0.104 \\
(0.126)\end{array}$ & $\begin{array}{c}0.477^{* * *} \\
(0.111)\end{array}$ & $\begin{array}{c}0.247^{* * *} \\
(0.084)\end{array}$ \\
\hline Mean of Dep. Var. & 0.81 & 0.37 & 0.84 & 0.34 & 0.65 & 0.32 & 0.82 & 0.30 & 0.41 & 0.23 \\
\hline Std. Dev. of Dep. Var. & 0.39 & 0.48 & 0.37 & 0.47 & 0.48 & 0.47 & 0.39 & 0.46 & 0.49 & 0.42 \\
\hline No. of Obs. & 796 & 795 & 1,057 & 1,055 & 725 & 719 & 986 & 989 & 1,089 & 1,094 \\
\hline
\end{tabular}

Note: Table reports the result of re-estimating the models in Table 2 excluding observations for individuals who responded "I did not do this before the pandemic" from the estimation sample. 